San Jose State University

SJSU ScholarWorks

Master's Theses

Master's Theses and Graduate Research

1993

\title{
The Effect of ethnically tailored diet education on a group of diabetic Punjabi elderly
}

Naranjan K. Singh

San Jose State University

Follow this and additional works at: https://scholarworks.sjsu.edu/etd_theses

\section{Recommended Citation}

Singh, Naranjan K., "The Effect of ethnically tailored diet education on a group of diabetic Punjabi elderly" (1993). Master's Theses. 583.

DOI: https://doi.org/10.31979/etd.g93g-k2wj

https://scholarworks.sjsu.edu/etd_theses/583

This Thesis is brought to you for free and open access by the Master's Theses and Graduate Research at SJSU ScholarWorks. It has been accepted for inclusion in Master's Theses by an authorized administrator of SJSU ScholarWorks. For more information, please contact scholarworks@sjsu.edu. 


\section{INFORMATION TO USERS}

This manuscript has been reproduced from the microfilm master. UMI films the text directly from the original or copy submitted. Thus, some thesis and dissertation copies are in typewriter face, while others may be from any type of computer printer.

The quality of this reproduction is dependent upon the quality of the copy submitted. Broken or indistinct print, colored or poor quality illustrations and photographs, print bleedthrough, substandard margins, and improper alignment can adversely affect reproduction.

In the unlikely event that the author did not send UMI a complete manuscript and there are missing pages, these will be noted. Also, if unauthorized copyright material had to be removed, a note will indicate the deletion.

Oversize materials (e.g., maps, drawings, charts) are reproduced by sectioning the original, beginning at the upper left-hand corner and continuing from left to right in equal sections with small overlaps. Each original is also photographed in one exposure and is included in reduced form at the back of the book.

Photographs included in the original manuscript have been reproduced xerographically in this copy. Higher quality $6 " \times 9$ " black and white photographic prints are available for any photographs or illustrations appearing in this copy for an additional charge. Contact UMI directly to order.

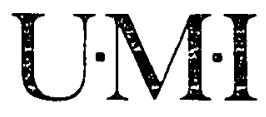

University Microfilms International

A Bell \& Howell Information Company 
Order Number 1359060

The effect of ethnically tailored diet education on a group of diabetic Punjabi elderly

Singh, Naranjan K., M.S.

San Jose State University, 1993

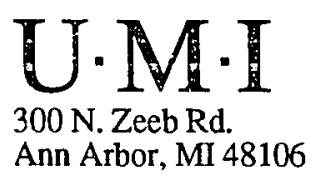



THE EFFECT OF ETHNICALLY TAILORED DIET EDUCATION ON A GROUP OF DIABETIC PUNJABI ELDERLY

\author{
A Thesis \\ Presented to \\ The Faculty of the Department of Nursing \\ San Jose State University
}

In Partial Fulfillment

of the Requirements for the Degree

Master of Science

by

Naranjan K. Singh

May, 1993 
APPROVED FOR THE DEPARTMENT OF NURSING

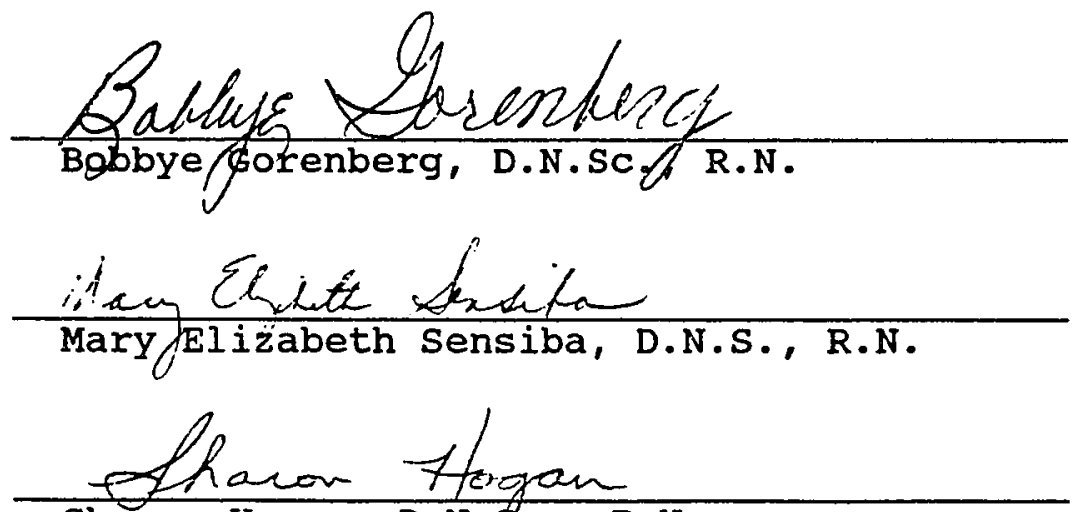

Sharon Hogan, D.N.BC., R.N.

APPROVED FOR THE UNIVERSITY

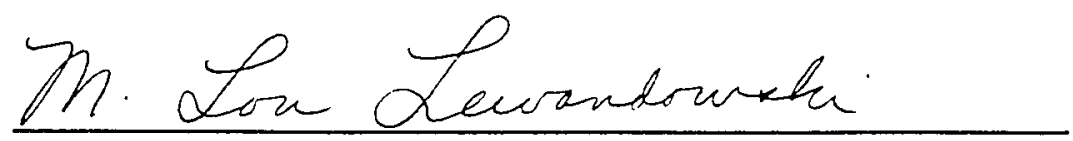




\section{ABSTRACT}

THE EFFECT OF ETHNICALLY TAILORED DIET EDUCATION ON A GROUP OF DIABETIC PUNJABI ELDERLY

by Naranjan $\mathrm{K}$. Singh

The purpose of this replicated and expanded study was to examine dietary compliance among a group of non-insulin dependent diabetic Punjabi American elderly when dietary teaching was ethnically tailored. Orem's (1991) self-care theory and Bandura's (1977) social learning theory were used as the conceptual framework. Utilizing a descriptive, modified case study approach, data were collected among a convenience sample of 6 Punjabi Americans. Their blood sugar levels were measured, and diet diaries were recorded and analyzed.

The data indicate that 5 out of 6 subjects showed improvement in their blood sugar levels. Five subjects showed dietary changes from the unacceptable level to the acceptable level though the consumption of food exchanges was not in total adherence to the American Diabetic Association diet plan. The results of pretest and posttest showed a knowledge gain in diabetes management and diet among all 6 subjects. 
ACKNOWLEDGEMENTS

MY humble submission to GOD for

His Divine Will and this accomplishment. My heartfelt thanks are due to:

Dr. Bobbye Gorenberg and Dr. Sharon Hogan who provided me with opportunity, inspiration, guidance, and support.

Dr. Betty Sensiba for her guidance and persistance in assisting me with this thesis.

My husband, Teja Singh, whose help and encouragement were invaluable.

Mị chilören, Teja Jr. and Ranjeeta, for their understanding and moral support. 
TABLE OF CONTENTS

Page

LIST OF TABLES . . . . . . . . . . . . . . . . vii

LIST OF FIGURES . . . . . . . . . . . . . . . . . viii

Chapter

1. INTRODUCTION . . . . . . . . . . . 1

The Problem . . . . . . . . . . 2

Purpose of the study . . . . . . . . . 4

Research Question . . . . . . . 5

Assumptions . . . . . . . . . 5

Definitions of Terms . . . . . . 6

summary - . . . . . . . . . . . 7

2. CONCEPTUAL FRAMEWORK AND REVIEW OF RELATED

LITERATURE • • . • • . • . . . . 10

Conceptual Framework . . . . . . . 10

Related Literature . . . . . . . . . 15

Summary • . • . . . . . . . . . 24

3. METHODOLOGY . . . . . . . . . . . 26

Research Design . . . . . . . . . 26

Subjects and setting . . . . . . . . 29

Human Subjects Approval . . . . . 30

Data Collection . . . . . . . . . 30

Instruments . . . . . . . . . . . . 34

Analysis Procedures . . . . . . . . 35 
4. FINDINGS AND INTERPRETATION . . . • . . 37

Interpretation of Findings . . . . . . 59

5. DISCUSSION . . . . . . . . . . 65

summary of study . . . . . . . . 65

Conclusions . . . . . . . . . . 66

Scope and Limitations . . . . . . . 67

Recommendations . . . . . . . . 69

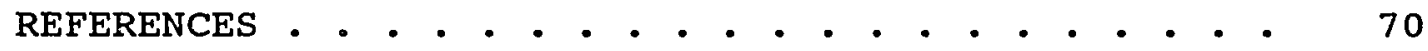

APPENDICES

A. Goals and Objectives . . . . . . 77

B. Outline of Teaching Course and Data

Collection Schedule . . . . . 79

c. Consent Letter . . . . . . . . 82

D. Food Questionnaire Form . . . . . 85

E. Pretest and Posttest . . . . . 87

F. Demographic Data Form . . . . . . 89

G. Diet Diary Form . . . . . . . . 91 


\section{LIST OF TABLES}

Table

Page

1. Blood Sugar Levels in $\mathrm{mg} / \mathrm{dl}(\underline{\mathrm{N}}=6)$. . . . 42

2. Dietary Compliance Comparison of All

Subjects $(\underline{N}=6) \cdot$. . . . . . . . . 43

vii 


\section{LIST OF FIGURES}

Figure $\quad$ Page

1. The Results of the Pretest and Posttest

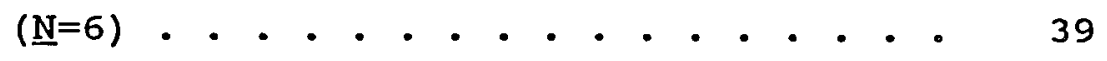

2. Trends of Blood Sugar Levels of Each

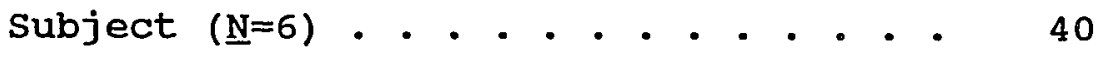


Chapter 1

INTRODUCTION

Dietary treatment is usually considered the cornerstone of metabolic control. Olson (1988) stated that "all diabetics, regardless of age or the severity of their diabetes, must be aware of the importance of dietary management" (p. 43). Studies analyzing diet habits and acculturation among migrants have shown that immigrant patients usually do not follow dietary recommendations due to cultural food preferences and language barriers. Results of a research study among a group of diabetic Koreans by $\mathrm{Kim}$ (1986) suggested that diet teaching with ethnic consideration had a positive effect on compliance with a diabetic diet.

Much like Koreans, dietary compliance of Punjabi diabetics migrating from India to the United states often follows a similar pattern of nonadherence. The dietary habits and ethnic food preferences of punjabis are different from Americans and other ethnic groups. Improvea knowledge and understanding of diabetic diet control in this American environment are needed. Thus, the research by Kim (1986) was replicated and expanded by the researcher to study dietary compliance among a group of diabetic Punjabi Americans when dietary teaching was ethnically tailored. 
The Problem

The population of Asian Americans in the United States in 1990 was 7.3 million and in the state of California was 2.8 million persons (Bureau of the Census, 1990). The prevalence of diabetes mellitus varies among different populations. In studies of diabetes mellitus the prevalence rates among various Asian groups were greater than among Caucasians (Fujimoto, 1985). In comparison with the European group, the South Asian group had a higher prevalence of diabetes- $-19 \%$ vs $4 \%--$ and a higher fasting and postglucose serum insulin concentration (McKeigue, Shah, \& Marmot, 1991).

A higher prevalence of diabetes has been reported in migrant Indians in South Africa, Fiji, Trinidad, Singapore, and Southhall, London (Zimmet, Taylor \& Ram, 1983). In Southhall, a survey showed that the prevalence of known diabetes in Indians (Punjabi) aged 40-64 was five to seven times greater than in Europeans (Allawi et al., 1988).

Increased numbers of immigrants who are Asians and Pacific Islanders are coming to the United States. Diabetes is increasing both among newcomers and those who have lived here for some time. In native Asian countries, the rate of Type II diabetes remains low. When researchers compared Asian Americans with people of similar age and ethnic background in their native country, there was a 
marked increase in diabetes among the U.S. groups (Lipson \& Kato-Palmer, 1988).

Blevins (1979), in her study of cultural change in health concepts and customs of three generations in an ethnic enclave, found that noncompliance with prescribed medical regimens was more common in diet than in medicine or physical therapy (p. 22). The American Diabetic Association (ADA) recommended in 1979 that meal plans be individualized in relationship to ethnic background and previous dietary habits.

First generation Punjabis who have migrated from Punjab, India tend to follow their previous dietary beliefs, habits, and meal plans. Common foods in the Punjabi diet are wheat, rice, dairy products, vegetables, fruits, root vegetables, kidney beans, pulses (dry legumes and lentils), and small amounts of protein provided by chicken, goat, and lamb. In a vegetarian diet, Punjabis use kidney beans, cheese, lentils, and legumes for protein substitutes. Dietary nonadherence is an important cause of poor metabolic control in both insulin-dependent and noninsulin-dependent diabetes.

Bhopal (1986) conducted a study of health beliefs of Punjabis in Britain. The report described "bhye bhaddi" which is a traditional Punjabi term describing an Asian concept of illness caused by dietary imbalance. Most 
Punjabis are conversant with that concept. Bhye bhaddi is related to an oversupply of certain foods including black gram (lentil), rice, cauliflower, and potatoes. Punjabis believe that these foods are "cold" which causes bhye bhaddi. To prevent bhye bhaddi, "hot" substances such as ginger, garlic, asofoetida, and karela (bitter gourd) are needed in their diet. Because of these health beliefs, management of aiabetes is a challenge.

Purpose of the study

The purpose of this study was to replicate and expand Kim's (1986) study. It's aim was to examine dietary compliance among a group of non-insulin-dependent diabetic Punjabi American elderly when dietary teaching was ethnically tailored.

Health care management strategies for people with diabetes mellitus primarily involve education. Lack of appropriate education can be costly both in financial and human terms. Punjabi immigrants have a high incidence of diabetes mellitus. Many Punjabi Americans have a limited command of English. Compliance is strongly influenced by the quality of communication and the amount of information given during the consultation and guidance process. A majority of Punjabis do not understand or are not able to interpret medical terms and concepts. Most of them follow their cultural health beliefs and practices which may not 
be appropriate for the diabetic treatment regimen. Therefore, there was a need to conduct a study such as this to establish and evaluate a diabetic diet education program tailored to Punjabi habits and customs. An ethnically tailored diabetic diet education program may improve the understanding and knowledge of diabetes mellitus among the Punjabi population.

\section{Research Question}

The primary research question was: What is the effect of an ethnically tailored program of diabetic diet education on dietary compliance in a group of elderly diabetic Punjabi American in northern California?

The objectives of the study were to (a) establish a baseline assessment of dietary habits from a group of elderly diabetic Punjabi persons, (b) incorporate the baseline findings into the implementation of an ethnically tailored diet education program, and (c) assess the effectiveness of the education program on compliance with the new diet by monitoring blood glucose results and by data analyses.

\section{Assumptions}

1. Punjabi American elderly would have dietary habits different from the dietary habits of other Americans. The target population would still adhere to their previous nutritional beliefs, habits, and meal plans including food 
patterns and methods of cooking and preparation.

2. The subjects participating in this study would have knowledge deficits in achieving dietary compliance that would maintain normal blood sugar levels.

3. Dietary education and counselling strategies would have a major influence on knowledge, compliance and metabolic control in the Punjabi diabetic sample.

\section{Definition of Terms}

For the purpose of this study, the following terms and definitions were applied:

1. Blood glucose monitoring (BGM) is a self-testing procedure utilizing the finger-stick method to determine blood glucose levels. The fingertip is punctured using an autolet or penlet and lancet. The blood drop is then smeared on a chemically treated strip (chemstrip bG) in accordance with the instructions and procedures specified by the manual accompanying the one-Touch, a blood sugar monitoring device made by Lifescan Inc., a Johnson and Johnson Company.

2. Dietary compliance is the act of conforming or acquiescing to the instructed diet regimen during treatment.

3. Diet diary is a record that shows the names of foods eaten, quantity of foods ingested, times of meals taken, and the cooking method used in preparing the food. 
4. Elderly are defined as persons who are aged 50 and over.

5. Ethnically tailored diabetic diet is a diabetic diet recommended by the ADA with six food exchange groups, where the food exchange list includes foods that are commonly used by Punjabi Americans. Customs of preparation and serving that are desirable are enhanced and habits that are undesirable are modified.

6. Non-insulin-dependent diabetic mellitus (NIDDM) is a diagnosis of diabetes mellitus made after the age of 40 years and for which oral hypoglycemic agents are used for treatment. NIDDM is also described as Type II diabetes.

7. Overweight is a weight which is 10-40 pounds above that recommended as normal "desirable" for height as taken from the Metropolitan Life Insurance Company's (1983) "Height and Weight Tables".

8. Punjabi American is a person who has migrated from Punjab, India to the United States and has legal permanent residency status.

\section{Summary}

Diabetes is a major problem world wide and is of increasing importance among immigrants from developing countries. The Southall Diabetes Survey in Britain revealed that the prevalence of known diabetes (predominantly NIDDM) was 5 to 7 times higher in Asians 
(mainly Punjabi sikhs) than British Caucasoids in the age group of 40 to 64. Furthermore, a study by Fujimoto (1985) revealed that the prevalence rates of diabetes among various Asian groups in the U.S. were greater than among Caucasians.

Nutritional management is a cornerstone of treatment for diabetes. One of the goals of nutritional therapy is to restore normal blood glucose and lipid levels. Immigrants coming to this country still retain a strong sense of their ethnic identity. For some, maintaining traditional food patterns is one way of preserving ethnic identity. Food habits are among those first learned and therefore last to change. Nutrient surveys indicate that compliance with dietary advice and control regimens does not only depend on peoples' belief, it must also be compatible with their cultural environment. For example, eating sweets is a basic part of the proceedings of Indian weddings, and even on a social visit, refusing to drink sweet tea or beverage when it is offered may cause offense. Punjabi immigrants have a high incidence of diabetes mellitus. A majority of Punjabis do not understand or are not able to interpret medical terms and concepts. Most of them follow their cultural health beliefs and practices which may not be appropriate for the diabetic treatment regimen. Every person with diabetes should have an 
individualized meal plan based on his or her personal diabetes management goal, life-style, and habits. Dietary recommendations should be realistic. Asking someone to completely change his/her eating habits is likely to be less effective than asking him/her to make simple adjustments. Studies have shown that suitable dietary education can have a major influence on knowledge, compliance, and metabolic control among diabetics. Orem's (1991) self-care theory and Bandura's (1977) social learning theory were used in this study as conceptual frameworks. They provided guidance to structure a diabetic diet education plan ethnically tailored for the subjects of this study. The investigator focused on the specific needs of the individuals, their environments, and habits to structure their meal plans and the teaching process. 


\author{
Chapter 2 \\ CONCEPTUAL FRAMEWORK AND RELATED IITERATURE
}

Conceptual Framework

The conceptual framework for this study is based on Orem's (1991) self-care theory and Bandura's (1977) theory of learning and imitation. Orem (1991) defines self-care as "the practice of activities that individuals initiate and perform on their own behalf in maintaining life, health, and well-being" (p. 117). Woods (1989) suggested that self-care has been a part of family life since the earliest documented civilizations. People have always assumed responsibility for their personal safety and for the well-being of the group or family within which they lived. The goal of the self-care theory is that people function and maintain life, health and well-being by caring for themselves.

According to orem (1991), self-care comprises the actions that individuals initiate on their own behalf to maintain life, health, and well-being. These actions are directed towards meeting three different types of self-care requisites: universal, developmental, and health-deviation requisites. The universal self-care requisites are common to all human beings during all stages of the life cycle. They are associated with the life processes, maintenance of the integrity of human structure and functioning, and 
general well-being. Developmental self-care requisites are associated with human developmental processes and conditions and with events that occur during various stages of the life cycle. Health-deviation self-care requisites are associated with persons who are ill, injured, have specific forms of pathology including defects and disabilities, and who are under treatment for medical conditions (p. 125).

Orem (1991) also introduces the concept of self-care agency which reflects the individual's limitations and abilities to provide the self-care requisites. Agency includes decisions about self-care as well as the actions required to accomplish self-care. The activities of self-care are learned according to the beliefs, habits, and practices that characterize the cultural way of life of the group to which the individual belongs (p. 145).

Self-care practices are therapeutic. These practices support life processes and promotion of normal functioning; maintain normal growth, development, and maturation; prevent, control or cure disease processes and injuries; and prevent or compensate for disability (Orem, 1991, p. 124)

Each person has self-care requisites. When self-care requisites are not met, therapeutic self-care demands exist. Health deviations, which create therapeutic 
self-care demands due to the self-care agency's limitations, lead the person from being a self-care agent to receiver of care. At this time self-care deficits occur. Fawcett (1989) stated that self-care deficits are calculated by determining the inadequacy of self-care agency in relation to self-care demand (p. 219).

Therapeutic measures for self-care deficits can be provided by applying one of the Orem's (1991) three related theories of nursing systems:

1. The wholly compensatory nursing systems in which a patient is unable to engage in any self-care action due to health deviations or deficits. The nurse's action accomplishes the patient's therapeutic self-care, compensates for the patient's inability to engage in self-care, and supports and protects the patient.

2. The partially compensatory nursing systems in which a patient performs some but not all self-care actions. The nurse's action performs some self-care measures for the patient, assists the patient as required and regulates self-care agency.

3. The supportive educative (developmental) nursing systems in which a patient is able to perform and learn care measures, but needs nursing assistance and help for decision making, behavior control and acquiring of skills for therapeutic self-care. 
Fawcett (1989) noted that the next step after selecting an appropriate nursing system for a subject is to select the appropriate method(s) of helping or assistance (p. 219). Orem (1991) describes five general methods of assistance by which one person can give help to others (a) acting for or doing for another, (b) guiding another, (c) supporting another (physically or psychologically), (d) providing an environment for personal development, and (e) teaching another (p. 8).

Diabetes mellitus is a chronic illness that requires active patient participation to maintain metabolic control. The regimen is complex and often necessitates changes in daily life and habits on the part of a person with diabetes and his/her family. The need for patient education in diabetes self-care practices has long been recognized (Funnel1, 1990).

Dietary treatment is usually considered the cornerstone of metabolic control. All diabetics, regardless of age or the severity of their diabetes, must be aware of the importance of dietary management (olson, 1988, p. 43). The nutrition management goals recommended by the American Diabetes Association (ADA) for individuals with diabetes are to (a) improve blood glucose and lipid levels, (b) promote consistency in day-to-day food intake and weight management, and (c) provide adequate nutrition 
for all stages of $l$ ife and coexisting medical conditions (ADA, 1988). Nutrition education is essential for the person with diabetes to achieve optimal blood glucose and lipid levels. Healthy and nutritionally adequate eating habits are important for everyone, but they are indispensable for the person with diabetes. It is important to introduce the concept of nutrition management in a simple understandable manner. Continuing education will help individuals incorporate nutritional management into their life-style.

Clients exposed to the diabetes educational process can utilize Orem's self-care model. A diabetic person has self-care demands that can exceed self-care agency. Therefore, in order for the diabetic self-care agent to meet the self-care demands, the calculated self-care deficit has to be met by education. For this study the researcher applied the supportive-educative nursing system. The methods of assistance were to guide another and teach another.

Lefrancois (1985) states that "learning is a change in human disposition or capability that persists over a period of time and is not simply ascribable to process of growth" (p. 20). His definition of social learning can be summarized as the acquiring of patterns of behavior that conform to social expectations in a given culture (p. 169). 
Furthermore, social learning could be described as a set of behaviors that are acceptable and also involve learning through social interaction. The social learning theory and concepts of imitation were applied to teach the dietary education to the target population in this study.

The concept of imitation simply means learning through simulation. It is also known as observational learning. Bandura's (1977) theory of social learning can be summarized in three statements (a) human learning is a function of observing the behavior of others, (b) we learn to imitate by being reinforced, and (c) imitation or observational learning is one of the fundamental means by which new models of behavior are acquired and existing patterns are modified (p. 16-39).

Related Literature

Diabetes mellitus is a chronic hereditary disease characterized by inappropriate hyperglycemia (Gambert, Cooppan, \& Gupta, 1990). According to Powers (1987), the metabolic disorder is due to a decrease in insulin activity resulting from either absolute or relative decrease in insulin concentration. This leads to abnormal metabolism of carbohydrate, protein and fat (p. 25). There are two types of diabetes mellitus:

1. Type I diabetes is an insulin-dependent diabetes mellitus (IDDM) in which the patient has a complete lack of 
insulin. To preserve life, patients have to depend on injected insulin. IDDM is most common in the white population and is thought to account for $10 \%$ to $20 \%$ of all known cases of diabetes mellitus. Although no known cause has been identified, it appears that genetic and environmental factors are causally related to IDDM (Gambert et al., 1990). Odugbesan and Barnett (1985) revealed that Asian diabetics have a lower prevalence of insulin dependence than Caucasian patients.

2. Type II diabetes is a non-insulin-dependent diabetes mellitus (NIDDM) which is most common in persons who are over 40 years of age and are obese or have a family history of diabetes. Type II diabetes is more common in black, Hispanic and native American populations (Gambert et al., 1990).

NIDDM has been particularly common in migrant Indian Asian communities in Britain and elsewhere. During a diabetes survey in Southhall, the study revealed that the prevalence of NIDDM was 5 to 7 times higher in Asian (mainly Punjabi Sikhs) than in British Caucasoids in the age groups of 40 to 64 years (Allawi et al., 1988). Mather and Keen (1985) in their "The Southhall Diabetic Survey" found that the prevalence of known diabetics among Asians living in Southhall was 5.3 times higher than that of Europeans. In the survey it was revealed that out of 1,143 
diabetic persons 761 (67\%) were Asians. Furthermore, 57\% of Asians were Sikhs. In the same study Mather and Keen stated that the prevalence of diabetes in India was not unusually high. In a study of 34,194 persons in India, the total prevalence of both known and new cases was $1.8 \%$. They also found that the prevalence of diabetes in Asians in Southhall was higher than in India. zimmet et al. (1983) found that high rates of diabetes are seen in groups that have undergone modernization of their way of life. Traditionally the Indian diet is essentially a low fat lactovegetarian diet (Raheja et al., 1987). Furthermore, the main source of fat in the diet is the cooking fat, usually from refined polyunsaturated or hydrogenated (saturated) vegetable oil. Animal proteins are usually provided by a limited quantity of milk and/or yogurt. other animal protein foods (meat, fish, eggs) are not consumed by a fair section of the population, but a majority who do consume these foods do so occasionally and sparingly. Intake of cheese is very limited. However, some families use eggs regularly. Rice and/or other cereals (whole grain) are taken in fair quantities at each and every meal. Pulses (dry legumes, lentils) are a regular item of daily diet. A variety of fresh vegetables is taken regularly after they are cooked and flavored with condiments and spices. 
Raheja et al. (1987) did a study on proliferation diabetic retinopathy (PDR) in patients with NIDDM who eat Indian diets. The experimental group ( $\underline{n}=15)$ had an Indian diet with animal proteins such as meat, fish, eggs, and cheese. The control group $(\underline{n}=50)$ had a similar diet except for animal protein foods (meat, fish, eggs). Results showed that all subjects in the experimental group developed PDR within 10 years after the detection of diabetes mellitus. In contrast, many subjects (number unspecified) in the control group remained free from PDR even after 20 years. Results showed that the PDR group had deviated from traditional Indian diet and consumed significantly more animal proteins from meats, fish, eggs, and cheese and more saturated total fats and less pulses and vegetables.

A high prevalence of obesity in a diabetic population and their food patterns were studied by Perkins, Plehwe, Hosking, and Turtle (1985) in Australia. A group of 252 adult diabetic patients was divided into categories according to their ethnic origin: (a) North European (including Australian, English, French and German); (b) Mediterranean (including Greek and Italian);

(c) Non-Indian Asian; (d) Lebanese; (e) Aborigine;

(f) Polynesian; and (g) Indian (including Pakistani). Data on dietary patterns, degree of obesity, and nutrition 
education status were collected. The major aim of the study was to identify areas where nutritional counselling was most needed among diabetics and the population at large. Results showed $61.5 \%$ of patients had had some nutritional counselling, $17.5 \%$ of patients had not received any nutritional advice, and the remaining $21 \%$ of patients were not sure if they had had diet education. The food histories were found to be too irregular to derive reliable estimates. The intake of proteins, fats, and carbohydrates was calculated. Males as a group had a significantly higher intake of each macronutrient (protein, fat, carbohydrate) than females, but had significantly lower relative fat and carbohydrate intakes than remales. The results were interpreted to conclude that there was a significantly higher prevalence of obesity in females when compared with males. Previous nutrition education did not appear to affect the prevalence of obesity.

The study by Perkins et al. (1985) also indicated that patients with previous dietary education had a belief in the value of reducing carbohydrate intake and consequently higher protein and fat intakes. There was no difference in carbohydrate intake between the three major ethnic groups. There was a high prevalence of obesity in all groups. This condition may be due to modification of traditional diets with Australian food patterns. The study revealed that 
people of Asian descent were less obese than the Northern European and Mediterranean groups. There was no comparison of other Asian and Indian groups in the study.

According to Singh and Chawla (1988), the total food intake of Punjabi Indian persons per day was 4,591 grams for vegetarian and 4,580 grams for nonvegetarian. The highest macronutrient in both diets was carbohydrates, and the second highest was milk and milk products. In the non-vegetarian diet, the animal protein supplied only 93 grams of the total. In the vegetarian diet, the protein consisted of 58 grams of peas and 47 grams of cheese.

The ADA (1991) recommends six food exchange groups for diabetic individuals--milk, vegetables, Iruits, starch and bread, meat with medium fat and high fat, and fats. The current nutritional recommendations for people with diabetes are: (a) carbohydrate intake may be up to 55-60\% of total calories; (b) protein intake $12 \%$ to $20 \%$ of total calories; (c) fat less than $30 \%$ of total calories; (d) fiber intake up to $40 \mathrm{~g} /$ day; (e) cholesterol intake less than $300 \mathrm{mg} / \mathrm{day}$; and (f) sodium intake not to exceed $3000 \mathrm{mg} / \mathrm{day}$.

Powers (1987) stated that "lowering of blood glucose and insulin requirements has been documented following ingestion of a large amount of fiber. The extremely high fiber diet consists primarily of bran, lentils, beans, and 
barley and is virtually a vegetarian diet" (p. 59). A study was done to evaluate the effect of a high fibre diet on glucemic status, serum lipid, and ischemic heart disease in Allahabad, India. Thirty-five non-insulin-dependent diabetic patients were given maize brain in their diet. The study concluded that treatment of diabetes with dietary fibre improves the diabetic control (Gupta, Sarita, Srivastava, \& Chaurasia, 1987). Punjabis seem to have high intakes of sugar, salt, milk, milk products, and fat. A refined butter called "ghee" is a very favorite dietary item among Punjabis. Their second favorite item is whole milk. Low fat milk is not commonly used among Punjabis. Wheat in the form of chapati (bread cooked on a hot plate) and rice are staple foods supplemented by panir (a curd-type cheese), milk and vegetable oil. A large proportion of fat intake among Punjabi people results from cooking spices in fat before the preparation of the entree and the practice of spreading butter on the chapatis which are served with every meal (Hodgson, 1989).

Compliance with dietary advice and control regimens not only depends on peoples' belief in the potential benefits of treatment, but also in the belief that the treatment is compatible with the cultural environment. Some aspects of Indian culture can make it difficult to 
comply with a diabetic control process. Eating sweets and meats is a basic part of the proceedings at Punjabi weddings and social visits. Refusing to drink sweet tea when it is offered may cause offense (Hodgson, 1989). Unfortunately, the researcher was unable to locate any studies of the nutritional status of Punjabis in the U.S. Dietary recommendations should be realistic. Asking people to completely change eating habits is likely to be less effective than asking them to make simple adjustments. McCulloch, Mitchell, Ambler, and Attersall (1983) stated that the actual deviation of patients' eating habits from their theoretical dietary prescription is surprisingly large, and also, that dietary policies should be simplified and made more flexible to suit each patient's life-style. Powers (1987) also recommended that the educational and counselling strategies, as well as the special meal plan, be individualized. A meal plan which is closely matched to the life-style of the patient may bring more successful results in compliance.

Ahmad, Baker, and Kernohan (1991) determined that compliance was strongly influenced by the quality of communication and the amount of information given during the consultation. Freimer, Echenberg, and Kretchmer (1983), in their study of cultural variations, found that the food practices of a transitional group were subject to 
pressures for change which may be environmental and cultural. Food habits may be appropriate in a particular environment yet may lead to nutritional deficiencies or disease under different conditions. Food habits may be altered in response to "demands" for acculturation. Such changes may either improve or worsen the nutritional quality of the diet.

studies comparing migrants and nonmigrants or acculturated and nonacculturated members of the same population have shown the strong association between obesity and the adoption of Western dietary habits and sedentary life-style. Obesity was highly correlated with NIDDM in many acculturating populations (Freimer et al., 1983). Most of the other chronic diseases that have been linked with acculturation and dietary change exhibit equally individual epidemiological characteristics. For instance, there was an increased prevalence of coronary heart disease among Japanese in California, in comparison with those in Hawaii and Japan. This increase in prevalence may have been associated not only with the adoption of American dietary habits but also with the development of American social and work habits (Marmot \& Syme, 1976). Freimer et al. (1983) emphasized considering the vulnerability of immigrant and acculturating groups to dominant cultural influences that may cause them to abandon 
nutritionally beneficial traditional foods for the heavily advertised, though less nutritional, foods of the new environment.

Kim (1986) did a research study using a case study design on the effect of ethnically tailored diet education with diabetic Koreans. This study was replicated and expanded in the present study. In Kim's study 4 noninsulin-dependent Koreans over the age of 45 years were selected. The blood sugar was measured, diet diaries were recorded, and ethnically tailored diet education was given for a period of 2 weeks. The data were analyzed using Ney, Stubblefield, and Fischer's (1983) dietary compliance system model and the results of the pretest and the posttest were compared. The results revealed that 3 of the 4 subjects showed changes from unacceptable levels to acceptable levels in their blood sugar and their dietary intakes. The pretest and posttest results showed that the subjects gained knowledge in their diabetic management and diet.

\section{Summary}

Diabetic mellitus is a chronic hereditary disease characterized by inappropriate hyperglycemia. It is a complex metabolic disorder affecting metabolism of carbohydrate, fats, and other nutrients. Appropriate nutrition management is essential for restoring and 
maintaining a normal metabolic state.

Type II diabetes (NIDDM) is most common in persons who are over 40 years of age and are obese. Studies revealed that NIDDM is particularly common in migrant Indian Asians (mainly Punjabi Sikhs) in the age group of 40 to 64 years. The dietary habits and ethnic food patterns of Punjabis are different from Americans and other ethnic groups. The characteristics of a Punjabi diet include a high consumption of carbohydrates (wheat and rice), butter, sugar, salt, milk, and milk products. Much like other ethnic groups, Punjabi Americans have been found to adhere to their previous nutritional beliefs, habits, and meal plans. Therefore, they should not be blindly encouraged into dietary habits simply because they are traditional. Instead, health care workers should recognize the power of cultural influences on nutritional health and make use of healthy traditional patterns of food consumption whenever appropriate to the prescribed diet.

The researcher was unable to locate any research studies regarding dietary habits, diabetic dietary education, and compliance among Punjabi Americans in northern California. Thus, it is apparent that there is a need to conduct a study such as this one to assess and establish an effective diabetic diet education program ethnically tailored to their habits and beliefs. 


\section{Chapter 3}

METHODOLOGY

Research Design

This study was descriptive utilizing a modified case study approach. LoBiondo-Wood and Haber (1990) stated that a case study is an in-depth investigation of one or few participants intended to provide detailed descriptions of the subjects and a large number of involved variables (p. 199). This method was selected to (a) replicate and demonstrate the effectiveness of Kim's (1986) study among a small sample of subjects in a Punjabi cultural setting, (b) establish a good source of descriptive information which can be used as evidence for or against future theories, and (c) provide a potential for important findings that may generate new hypotheses for testing (Burns \& Grove, 1987, p. 250). It is important to examine all variables in order to establish a self-care agency. The scope of this study included establishment of a baseline assessment of dietary habits of 6 Punjabi Americans who have NIDDM. The investigator identified the age and sex, studied the food habits and patterns, environmental situations, acculturation influences, knowledge regarding disease and ADA diet, and compliance of the subjects. An ethnically tailored diet plan was developed and diet education was provided to each subject 
during a home visit by the researcher.

This study was designed in three phases:

1. Baseline data collection for the first 2 days.

2. Administration of the treatment (dietary assessment and diet teaching) for 6 days.

3. Reinforcement of treatment for 2 days. Two weeks after the completion of the 10-day study, follow-up visits by the investigator were also planned to review their diet compliance by testing blood sugar levels. An initial preliminary home visit was made to explain the goals and objectives of this study to each subject (Appendix A). The subjects were assessed for dietary compliance and then a dietary plan was developed and tailored for them on an ethnic basis. An outline of teaching and a data collection schedule were developed and implemented for all subjects (Appendix B). After obtaining the consent (Appendix C) from each participant, the ethnically tailored diet education program was implemented among the 6 elderly Punjabi Americans for a period of 2 weeks. The researcher made visits on Monday through Friday of each week, though the subjects were asked to follow the diet program on the weekends as well.

Throughout the three phases, identical pretests, posttests, and questionnaires were given to maintain standardization. The content, diet education plan, 
methodology, and duration of teaching were individualized according to the subject's self-care requisites. However, the same course outline was utilized for teaching all subjects during the three phases of the study (Appendix B). The food questionnaire (Appendix D), the pretest and posttest (Appendix E), and other administrative formats were modified by the researcher to suit the Punjabi cultural environment. The baseline data collection included the demographic data and medical history (Appendix F), pretest of diabetes and dietary knowledge, and a questionnaire regarding dietary habits. Each subject was asked to maintain a record of daily diet in a diary (Appendix G) during the treatment and reinforcement phases. Compliance and effectiveness of the dietary education plan was monitored daily during the teaching and reinforcement phases of the 2 -week study through taking blood glucose levels and evaluating the diet diaries. A posttest was given on the second day of the reinforcement phase to assess the knowledge gain. At the end of the second week, dietary compliance was again assessed. Two weeks after the completion of the study, the investigator visited the subjects to review and follow-up the dietary management for compliance. Blood sugar levels were also obtained. 
Subjects and setting

Criteria for participation in this study were that the person was (a) Punjabi with legal residency; (b) over 50 years of age; (c) diagnosed as having NIDDR and taking an oral hypoglycemic agent; and (d) able to speak, read, or write Punjabi or English. Final selection was determined by the subject's willingness to participate in the study. The study was carried out in an urban area of northern California where a large population of Punjabi Americans were residing.

The convenience sample of 6 elderly Punjabi Americans was selected from the membership of a local sikh temple. All of the 6 participants were sikhs by religion and belonged to the same sikh community of northern California. Four of the subjects were referred by a Punjabi physician who was in private practice in the same area. The other two were not referred by a physician, but were temple members who voluntarily responded to the researcher's request for participation in this study.

\section{Human Subject's Approval}

Once the research proposal with the intended instrument was formulated, the study was submitted to the Institutional Review Board (IRB), Human Subject's Committee of San Jose State University (SJSU) for review and permission to conduct the study. Permission was granted on 
a "minimal risk to human subject" basis. It was clearly spelled out that all individual responses would be kept strictly confidential. Upon completion of the Master's thesis all the personal data regarding subjects would be destroyed. Following approval from the IRB Human subjects Committee formal consent (Appendix C) was obtained from each participating subject for participation and permission for home visitation.

\section{Data Collection}

An ethnically tailored diet education program was implemented among the 6 elderly Punjabi Americans for a period of 2 weeks in three phases: (a) baseline data collection for the first 2 days, (b) administration of the treatment (dietary assessment and diet teaching) for 6 days, and (c) reinforcement of treatment for 2 days.

The researcher made home visits on Monday through Friday of each week though the subjects were asked to follow the diet program on the week ends as well. The research period was from April 20, 1992 to May 1, 1992. The follow-up visits were made on May 15, 1992 (2 weeks after the completion of the 10-day study period) to review diet compliance by testing subjects' blood sugar levels. The diet teaching was performed in 30 minute sessions each day by the researcher. The investigator began each teaching day with a specific diabetic diet topic and 
encouraged the participants to describe what had previously been taught. Explanation was done with handouts and written materials for a specific topic. The participants were encouraged to ask questions regarding what had been and would be discussed.

The researcher utilized Bandura's theory of learning and imitation (observational learning theory) during the teaching process. Bandura (1977) stated "After watching models perform novel behavior, observers can later describe the behavior with considerable accuracy, and given appropriate inducement, they often achieve errorless enactment on the first trial" (p. 35).

The investigator began each teaching day with a brief review of the previous day's presentation in an effort to utilize Bandura's role of reinforcement in observational learning. Bandura (1977) stated that anticipation of reinforcement is one of the factors that can influence what is observed and what is noticed (p. 37). The same outline of the teaching course and data collection schedule was followed for all patients.

\section{Baseline Data Phase}

The investigator made an initial preliminary home visit to meet the subjects and their families, and to explain the study. Baseline information such as demographic data, the previous dietary habits of the 
subjects, initial blood glucose level, medical history, anã their knowledge of disease and diet was collected in the first 2 days. During the 1st day of the baseline data phase, the signed consent forms, demographic data, the dietary habit questionnaires, and blood sugar levels were obtained. On the 2 nd day, the pretest was completed by each participant. Also, the goals and objectives (Appendix A), and an outline of teaching course and data collection schedule (Appendix B) were explained.

\section{Treatment Phase}

The diet teaching was conducted for 6 days, from the 3rd to the 8 th day. During each visit, the ethnically tailored diabetic diet education was provided in a half-hour session to the patient and family. Teaching and guidance was provided by the investigator at the subject's home. The social learning theory and concepts of imitation were applied to teach dietary education. The participants maintained daily records of each time food was consumed during the 6 day study period. Compliance and effectiveness of the dietary education plan were monitored daily during the teaching and reinforcement phases by taking blood glucose levels. During each session with a subject, questions and answers regarding diet and other problems in diabetic management were discussed. Each day of visit the investigator reviewed the diet diary and the 
participant was asked to adjust the exchanges if they were unacceptable. Also, the investigator reviewed and discussed the previous day's teaching with the subjects.

\section{Reinforcement Phase}

The reinforcement phase was on the 9 th and 10 th days of data collection. The diet diaries were reviewed for corrections or replacements, if required. On the 10th day a posttest was completed by each participant. The same pretest questionnaire was used for the posttest to maintain standardization. Questions and answers regarding diet and other problems in diabetes management were discussed. Two weeks after the completion of the study, the investigator made home visits to each participating subject to follow-up and review if the subject had followed the recommended diabetic diet plan. Blood sugar levels were also obtained.

The researcher performed the test and monitored the blood sugar level for each participant during the teaching, reinforcement and follow-up phases to verify the patient's compliance. A testing procedure utilizing the finger-stick method was used to determine blood sugar level. The fingertip was punctured using an autolet or penlet and lancet. The blood drop was then smeared on a chemically treated strip (chemstrip bG) in accordance with the instructions and procedures specified by the manual accompanying the one-Touch blood glucose monitoring device. 
The blood sugar level was indicated on the one-Touch reflectance meter. Records of the results were maintained. An individual diet diary was maintained by each participant for the 10 days of the teaching, treatment, and reinforcement phases of the study. Household measuring utensils (standard cups and spoons) were used to measure foods by the participant at his/her home. The diet diaries were analyzed by the investigator in accordance with the modified model of Ney, Stubblefield, and Fischer's (1983) dietary compliance system. The collected data were analyzed using descriptive statistics.

Instruments

The data collection instruments were a demographic data questionnaire, a one-Touch blood glucose monitoring system, daily diet diary, and food questionnaires. Food questionnaires were initially developed by Kim (1986) for use in a Korean study. The investigator made some changes in the food and pretest questionnaires (Appendices D and E) to fit Punjabi food items and diet terminology.

The investigator performed the blood glucose checks daily for the 10-day study period. Furthermore, the tests were performed approximately at the same time at each visit. The blood sugar testing was done by a finger prick, using the penlet, a sterile lancet, a chemstrip, and the one-Touch reflectance meter. The daily food intake was 
recorded by the participants on the daily diet diary (Appendix G). The amount of each food item consumed by the participants was measured by the participants using household measuring utensils, such as standarả cups and spoons.

Modified formats of the two questionnaires developed by Kim (1986) in the Korean study (Appendices D \& F) were used in this study to collect demographic and dietary habits data. These questionnaires were completed by each participant during the first home visit. The investigator used the previous study's pretest form with changes in food items according to participant's ethnic food pattern (Appendix E). The same pretest questionnaire was used for both the pretest and the posttest activities to test the knowledge of each participant regarding diabetes and diabetic diets. The pretest was given on the 2 nd day of the study and the posttest was given on the loth day of data collection.

The reliability and validity of the measurement instruments were not established in the present or previous studies. The instruments were discussed with the Punjabi physician, but formal content validity was not obtained. Analysis Procedures

Data were analyzed using the modified model of Ney et al.'s (1983) dietary compliance system (NDCS). The NDCS 
has three classification categories for dietary compliance: good, acceptable, and unacceptable. Criteria for good compliance were: (a) 75 to $110 \%$ of prescribed exchanges were consumed; (b) meals were consumed within one-half hour of normal time at least $75 \%$ of the time; and (c) high sugar foods were consumed one time or less per week. Criteria for unacceptable compliance were: (a) less than 50\% or more than $125 \%$ of prescribed exchanges were consumed; (b) total number of prescribed meals were consumed less than $50 \%$ of the time; and (c) high sugar foods were consumed more than 3 times per week. Criteria for acceptable compliance were obtained when all of the criteria were not met for either the good or the unacceptable compliance categories. 


\section{Chapter 4}

\section{FINDINGS AND INTERPRETATION}

The subjects of this study consisted of 6 Punjabi American elderly persons between 50 to 75 years of age. The mean age of the subjects was 64.8 years. There were 2 males and 4 females. All the participants have been residing in the United states for more than 2 years. The mean residence duration was 9.5 years. All individuals had NIDDM and were on an oral hypoglycemic agent. Three subjects were overweight and 3 were within the normal range. Weights of the participants were compared with the figure given in Metropolitan Life Insurance Company's (1983) "Height and Weight Tables" to determine if a subject was overweight.

The study was conducted in three phases which included (a) baseline data collection for 2 days, (b) administration of the treatment (dietary assessment and diet teaching) for 6 days, and (c) reinforcement of treatment for 2 days. The daily diet diaries of each participant were examined to evaluate the effectiveness of the ethnically tailored diet education plan, using a modified NDCS model. The blood glucose levels were measured for 10 days during three phases on each of the 6 subjects. The small size of the sample used in this research did not warrant statistical analysis of the data. Results were compared for 
effectiveness of the diet education plan. The results of the analysis are presented in Tables 1 and 2. The findings of the descriptive case studies are outlined in the following sections and the data are displayed in Figures 1 and 2 .

\section{Subject 1}

Subject 1 was a 53-year-old male who had had diabetes for 3 years and had been in the United States for 24 years. He took oral hypoglycemic agent (Diabeta) $2.5 \mathrm{mg}$, one tablet every morning. His weight was above normal and the average of his blood pressure readings taken daily during the 10-day study period was $146 / 90$. He lived with his wife, son, daughter-in-law, and three grandsons. His wife and daughter-in-law did the cooking for him. According to the food questionnaire, he ate Westernized breakfasts and lunches every Monday through Friday and he took Punjabi food every evening and on weekends. When he had Punjabi food, he recorded butter, regular sour cream, regular buttermilk, chutney, and catsup as frequently used seasonings. The pretest score on knowledge of diabetes was $85 \%$ and the posttest score was $97 \%$ (see Figure $1, \mathrm{~S} 1$ ). His blood sugar levels were tested each day by the investigator approximately 2 hours after his breakfast. The blood sugar results and the trend of the blood sugar levels are shown in Figure 2, subject 1 . The average of 


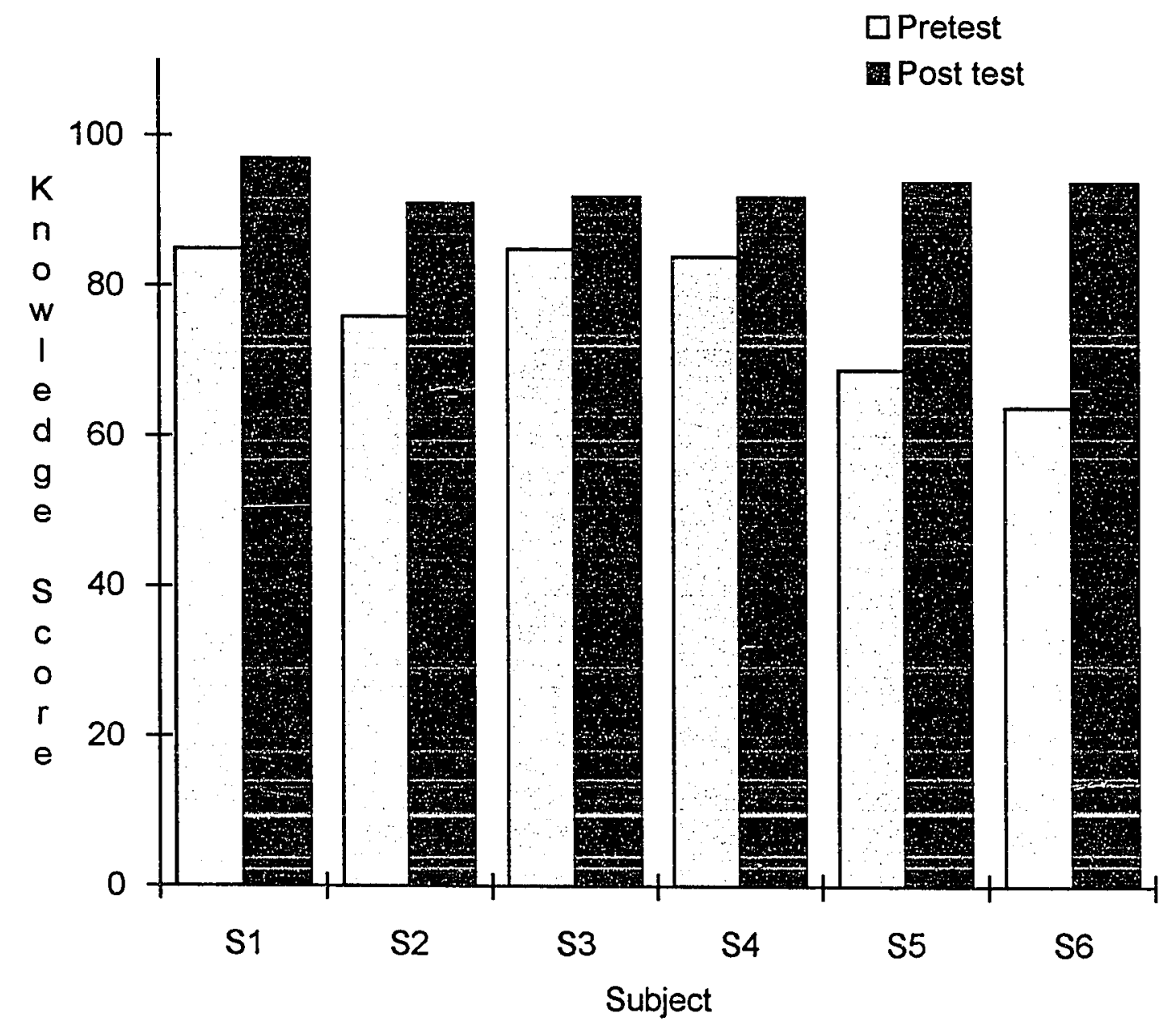

Figure 1. The Results of the Pretest and Posttest $(\underline{\underline{N}}=6)$. 

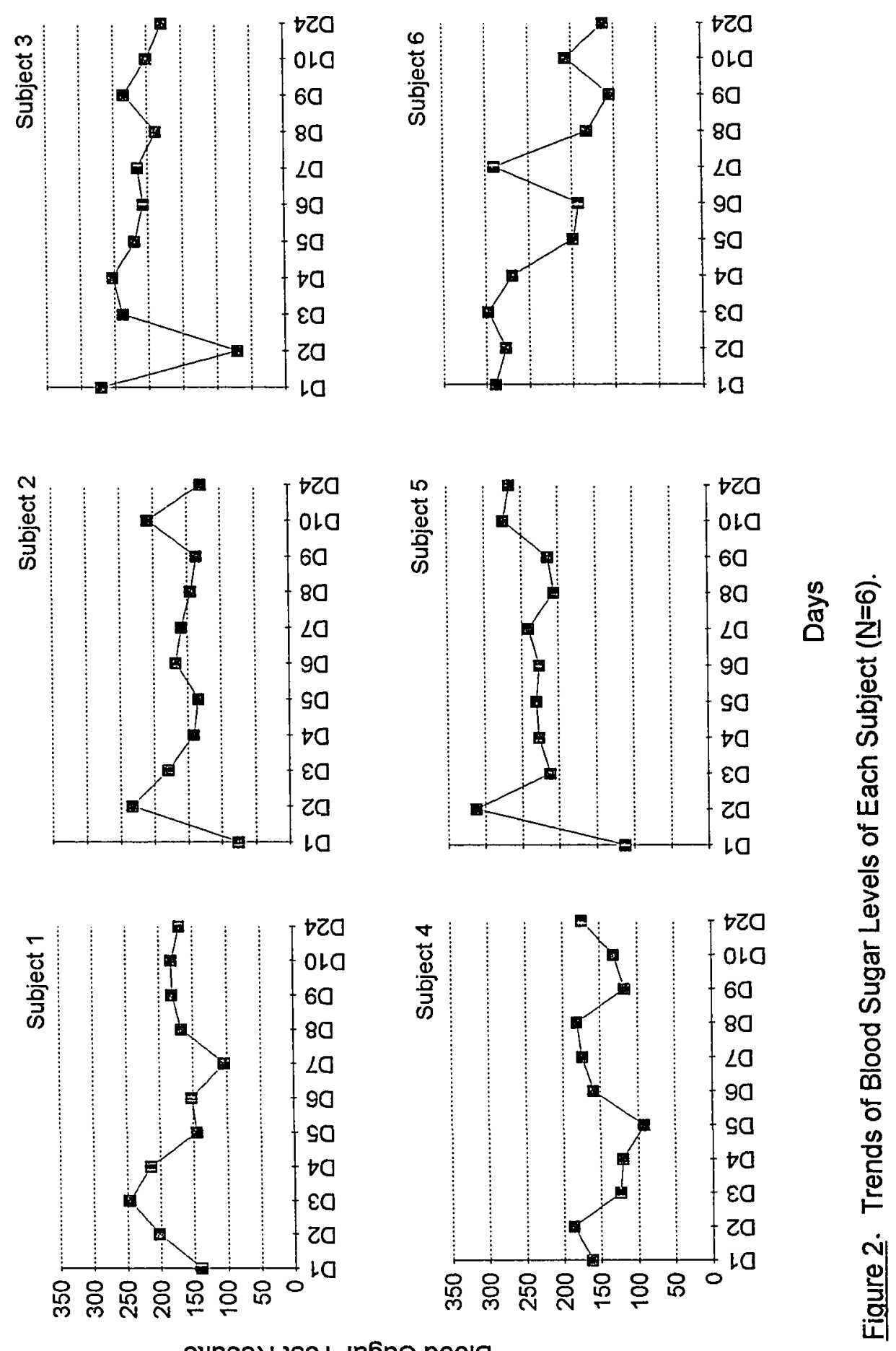

słjnsay łsa 1 Je6̂ns poolg 
his blood sugar levels taken during the 2 day baseline data phase was 171. His blood sugar level increased to 247 on the first day of the second phase. He stated that he had a relative visiting during that time and was unable to follow the diabetic diet plan properly. Moreover, he had two drinks of alcohol with his relative and friends. During the second phase, from the 3rd to the 8th day, his blood sugar gradually decreased from 247 to 167 . Blood sugar level averaged 171.5 in this 6 day treatment phase. During the reinforcement phase, his average blood sugar increased to 181.5. His blood sugar levels during 10 days showed a declining trend during the treatment phase. Two weeks after the completion of the 10-day study his blood sugar was 170 (see Table 1, SI).

The subject was on a 1500 calorie diet plan, but he was not following his physician's prescribed diet. He reported that he had no idea how to calculate the meal plan with exchange lists. He had not measured foods prior to this ethnically tailored diet plan. According to his diet diary, he had an unacceptable level of daily diet intake. For example, on Day one he had nine exchanges of bread and starch instead of six exchanges. He had no intake of fruits and used excessive fat exchanges. According to the ADA diet, $50 \%$ of the calories should come from starch and bread groups, $20 \%$ from protein exchanges, and $30 \%$ from fat 


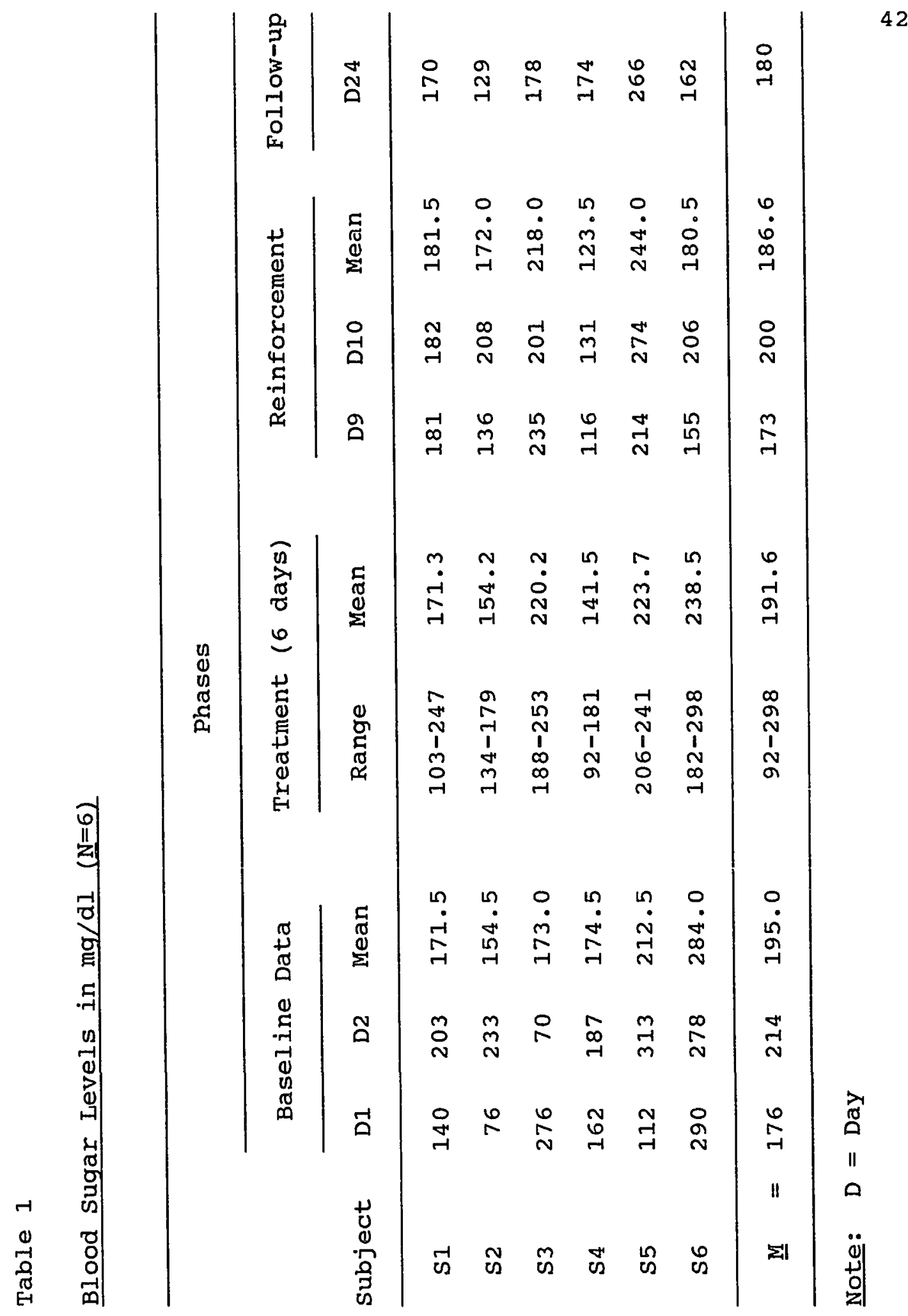


Table 2

Dietary Compliance Comparison of All subjects $(\mathrm{N}=6)$

\begin{tabular}{|c|c|c|c|c|c|c|c|}
\hline \multicolumn{2}{|c|}{ ADA Prescribed } & \multirow[t]{2}{*}{ Total } & \multirow[t]{2}{*}{ Calories } & \multicolumn{2}{|c|}{ s Consumed by } & \multirow[t]{2}{*}{ Subject } & \multirow[t]{2}{*}{$(\%)$} \\
\hline Exchange & $\%$ of & & & & & & \\
\hline Group & Total & S1 & $\mathrm{s} 2$ & S3 & S4 & S5 & S6 \\
\hline Starch/Bread & 50 & 82.5 & 95.8 & 95.0 & 74.2 & 84.2 & 82.5 \\
\hline Meat/Subs. & 20 & 9.5 & 0.5 & 7.5 & 1.3 & 1.0 & 1.0 \\
\hline Fats & 30 & 34.0 & 31.0 & 33.0 & 34.0 & 35.0 & 40.0 \\
\hline
\end{tabular}

Note: Total calories consumed by each subject during the 10-day study period, for a particular exchange group, are shown as percentage of the total calories prescribed for the exchange group in the 1500 calorie diet plan. 
exchange groups. His starch/bread exchange intake was $82.5 \%$, protein was $9.5 \%$, and fat was $34.0 \%$ of his prescribed diet calories (see Table 2, S1). He had extra calories from alcoholic drinks. Moreover, he used regular juices for beverages. His breakfast and lunch meal times were regular but his dinner meal times were irregular. During the treatment and teaching phase, from the $3 \mathrm{rd}$ day to the 8th day, he gradually decreased starch and bread intake. His alcohol intake decreased. His food intake was still at an unacceptable level and he omitted the fruit exchange group. On the 6th day, his food intake level reached the acceptable compliance level and his blood glucose was 152 . On the 7th day, his compliance level was acceptable and blood glucose level decreased to 103 .

During the reinforcement phase, the blood sugar level increased to an average of 181.5 . He reported that he had some Indian sweets. His dinner meal time was becoming regular. He even had steamed vegetables instead of fried. Moreover, he started to use his fruit exchange. He lost 2 pounds of weight during the 10-day study period. Two weeks after the completion of the reinforcement phase, during the follow-up visit, his blood sugar level was 170 which indicated that the subject had followed the recommended diabetic diet plan. 
Subject 2

Subject 2 was a 66-year-old female who had had diabetes for more than 5 years. She had been in the United states for 5 years. Her prescribed oral hypoglycemic medication was Micronase $5 \mathrm{mg}$, one tablet every morning. Her vital signs were within normal range, and her weight was also in the normal range. She had heart surgery 3 years ago and had a history of hypertension. She lived with her husband, son, and son's family. She cooked most of the time except on weekends when her daughter-in-law cooked for her. She took care of her three grandchildren when her daughter-in-law was at work. She was vegetarian and ate Punjabi food most of the time. She used hot pepper sauce, ketchup, chutney, panir (homemade thick white cheese), oil, and sugar as seasonings. She used sugar occasionally to make sweet rice and Indian sweets. According to her food questionnaire, she dined out once a week and had cheese pizza and french fries. Her prescribed diet was for 1500 calories but she did not follow it. She had not received proper diabetic diet education prior to this plan. She did not have any testing instrument for monitoring her own blood sugar level. Instead, she visited her physician every 2 to 3 months for her blood tests. Her initial knowledge score was 76 at pretest which improved to 91 at posttest (see Figure 1, s2). 
Her blood sugar levels were tested by the investigator 1 hour after breakfast. Her blood sugar level averaged 154.5 during the baseline data phase, 154.2 during the treatment phase, and 172 during the reinforcement phase. Two weeks after the completion of the reinforcement phase her blood sugar was 129 (see Table 1, S2). On the very 1st day of this study her blood sugar level was 72 and on the 2nd day it had increased to 233 (see Figure 2, subject 2). She reported that on the lst day she got so busy with her grandchildren that she did not take breakfast and medication on time. That night she was unable to sleep but did not know the cause.

During the baseline data phase, her diet diarȳ showed that she had 13 starch and bread exchanges instead of 6 as indicated in her 1500 calorie prescribed diet. Her diet menu was lacking in the fruit exchange. Her meal times were irregular and she was not measuring her daily food intake. She reported that she did not like to measure her food intake because she believed that it was against Indian tradition.

During the treatment phase her daily intake was at an acceptable level, but her fruit and meat substitute exchanges were not sufficient. From the 3 rd to the 5 th day her daily intake still continued to be excessive in the starch and bread exchange groups. She used food with high 
sugar content on weekends. Her meat substitute iritake was very low as compared to the suggested $20 \%$ of the total calories of the prescribed diet. From the 6 th to the 8 th day she reduced the starch and bread exchange. She started eating one chapati (Indian bread) instead of two at each lunch and dinner meal. She started using more vegetable exchanges instead of dal (lentils) which fell into the category of bread exchange. Her daily diet diary showed appropriate levels of the intakes during the 7 th and 8 th days.

During the reinforcement phase on the 9 th and 10 th days her diet intake was at an acceptable level. She followed the recommended dietary exchange. However, her blood sugar on the 10th day was 208. She reported that she was not feeling well. Her average consumption of calories for the 10-day study period was $95.8 \%$ for the starch and bread group, $0.5 \%$ for meat and meat substitutes, and $31.0 \%$ for fats (see Table 1, S2). Two weeks after the completion of the reinforcement phase, her blood sugar level was 129 which indicated that the subject had benefited from the teaching of the ethnically tailored diabetic diet plan.

Recommendations were made to use less oil during cooking, to decrease the starch and bread exchange group, and to use enough fruit exchanges in her menu. The significance of taking prescribed amounts of food intake 
and the measurement of food with household measurement utensils were explained. Also, the importance of regular meal times and of regular home blood sugar testing was emphasized.

\section{Subject 3}

Subject 3 was a 65-year-old male who had been diabetic for 20 years. He had been in United States for 1 year and had been treated for hypertension. His admission day blood pressure was 160/100. He was taking oral hypoglycemic agent (Glucotrol) $5 \mathrm{mg}$ tablet, 2 times a day. His weight was within normal range. His physician had prescribed a 1500 calorie diet, but he reported that it was difficult for him to follow. He was not very happy in the United states and would have liked to go back to his colleagues in India. He was retired and lived with his wife, son, and the son's family. His wife and daughter-in-law prepared meals for him. He walked 3 miles each day for his exercise.

According to his food questionnaire, he ate mostly Punjabi food. His wife or daughter-in-law cooked for him using hot pepper sauce, ketchup, chutney, butter, corn oil, panir (homemade thick white cheese), and whole milk as frequent seasonings. He dined out once or twice a month, having meals consisting of pizzas, hot dog, hamburgers, and/or french fries. He reported that he used one to two 
drinks of alcohol 2 to 3 times a week. His pretest score on diabetic knowledge was $85 \%$ and the posttest score was $92 \%$ (see Figure 1, S3).

His blood sugar levels were tested by the investigator approximately 1 hour before lunch. The blood sugar level averaged 170.5 during the baseline data phase, 220.2 during the treatment phase, and 218.2 during the reinforcement phase. The blood sugar test, 2 weeks from the completion of the reinforcement phase, showed his blood sugar level of 178. His blood sugar during the treatment and teaching phase showed a declining trend (see Figure 2 and Table 1, S3). During the 10-day study, his starch/bread exchange intake was $95.0 \%$, meat/substitutes was $7.5 \%$, and fat was $33.0 \%$ of his prescribed diet calories (see Table 2, s3). The baseline diet diary showed an unacceptable level of daily diet intake. He used 11.4 (95\%) starch and bread exchange instead of $6(50 \%)$ according to 1500 calorie diet recommended by the $\mathrm{ADA}$. He had extra calories from alcoholic drinks. His meat exchange group was much less than the recommended $20 \%$. There was no fruit exchange in his menu. He used excessive fat exchange in his daily diet. However, his meal time and snack time were regular each day.

During the treatment phase from the 3 rd day to the 6 th day, his daily intakes were at unacceptable levels. His 
starch and bread exchange intake was excessive. He was not taking enough fruit and meat exchanges. On the 7 th and 8 th days of the treatment phase his starch and bread exchange group decreased and he was taking all of the recommended exchanges. Also, his daily intakes became acceptable. During the reinforcement phase on the 9 th day his blood sugar was 235. He reported that he took two alcohol drinks on the night before. On the loth day his blood sugar was 201 and his daily intake was at an acceptable level. Two weeks after the completion of the reinforcement phase, his blood sugar level was 178 which indicated a favorable trend of compliance and a positive effect of the ethnically tailored diabetic diet.

The investigator made the following recommendations to the subject and his family: (a) to decrease the daily intake carbohydrates (starch/bread), (b) to use less fat in cooking and preparing food, and (c) to check and record blood sugar level daily. The investigator reported his blood sugar levels to his physician.

\section{Subject 4}

Subject 4 was a 62-year-old female who had had diabetes for 9 years and had been in the United States for 10 years. She was taking oral hypoglycemic agent (Diabinese) $250 \mathrm{mg}$, one tablet every morning. Her vital signs were within normal range, and her weight was also in 
the normal range. She reported that initially she used urine testing to check and monitor her glucose levels. Recently her son had purchased a one-Touch blood sugar monitoring device which she has been using to monitor her blood sugar level once a week. Her prescribed diet was a 1500 calorie diet plan. She reported that she was not able to follow her prescribed diet for lack of understanding and knowledge of the diabetic diet exchange system. She lived with her husband who was also a diabetic patient, her son who was a borderline diabetic, and the son's family. She cooked for herself and the family members most of the time. Occasionally her daughter-in-law cooked her meals.

According to her food questionnaire, she was a vegetarian and ate only the Punjabi food. She ate three meals a day with snacks and tea at 3:00 PM everyday. She dined out on some sundays only when she went to the temple. Her main food consisted of chapati (Indian braad), dal (lentils), and vegetables. She used frequently chutney, ketchup, hot pepper sauce, sugar, butter, ghee (clarified butter), oil, panir (homemade thick cheese), and homogenized whole milk in her meals. Regarding her knowledge about diabetes, her pretest score was 84 which improved to 92 at the posttest (see Figure 1, S4). The investigator checked her blood sugar levels about one-half hour before lunch. Her average blood sugar levels 
were 174.5 during baseline data phase, 141.5 during treatment phase, and 123.5 during reinforcement phase. Two weeks after the completion of the reinforcement phase her blood sugar level was 174 (see Table 1, S4).

During the baseline data phase, her daily diet diary showed no intake of fruit and meat substitute groups, starch and bread intake of $82.13 \%$ instead of $50 \%$, and fat intake of $43 \%$ instead of $30 \%$ according to her prescribed diet. Her compliance was at an unacceptable level. During the treatment and teaching phase her diet habits improved but were still at an unacceptable level. She had only one exchange of fruit and three exchanges of meat substitute in her diet during the 6 day treatment period. The use of starch and bread exchange group came down from $82.13 \%$ to $71.86 \%$ which was still too high from the recommended level of $50.0 \%$ of the prescribed diet. However, her fat intake came down to the recommended $30 \%$ level.

The subject showed significant improvement during the reinforcement phase. Her intake of starch and bread decreased to $51.3 \%$ and she started to add fruit and meat substitutes in her menu. Her fat exchange stayed at the recommended $30 \%$ level. On the loth day of the study period her blood sugar level was at 131, and her compliance was at an acceptable level. 
Subject 5

Subject 5 was a 70-year-old female who had had diabetes for 15 years and had been in the United states for 4 years. She was taking Glucotrol, oral hypoglycemic agent, $5 \mathrm{mg}$, two tablets 2 times a day. She had a history of hypertension and heart disease. She lived with her daughter, son-in-law and three grandchildren. She took care of her grandchildren during the day when her daughter was at work. Her average blood pressure for 10 days was 139/76 with twice a day hypertension medication. Her average heart rate for 10 days was 81 with normal rhythm. She reported that she used to test her urine every morning to check her glucose level, but lately with her grandchildren to take care of, she hardly found time and/or became too tired to perform the tests. She also reported that she was supposed to be on a 1500 calorie diet plan, but never measured the food intakes. She prepared her meals during the day, and her daughter cooked the evening meals. Prior to this study, the only education she acquired was that she should not take any sugar, fried food, and excessive fat. Her pretest score on diabetic knowledge was $69 \%$ which improved to $94 \%$ at the posttest (Figure 1, S5).

According to her food questionnaire, she was vegetarian and ate only Punjabi food. She had three meals 
a day and one snack dish in the afternoon. Her dinner time was between 8:00 PM to 9:00 PM every day. She dined out twice a week when she went to the temple on Wednesday and sunday. She reported that she did take sweets and desserts if offered at the temple. Her main seasonings in the daily menu were chutney, panir (homemade thick white cheese), margarine, ghee (clarified butter), lowfat milk, and Indian sweets.

Her daily blood sugar tests were performed by the investigator about half an hour before lunch. Her average blood sugar levels were 268.5 during the baseline data phase, 223.7 during the treatment phase, and 244 during the reinforcement phase. Her blood sugar level after the 2 weeks from the last day of the data collection was 266 . (see Table 1, S5).

During the baseline data phase, her diet diary showed starch and bread intake of $82.13 \%$ instead of $50.0 \%$ of the recommended diet exchange. Her meat substitute and fruit exchange intake were not sufficient. Her fat intake was $43 \%$ rather than $30 \%$ as recommended. She had some Indian sweets in this period as well. Her compliance level was unacceptable.

During the treatment phase, her daily diet intake records were incomplete for the 5 th and 7 th days. She said that she was too busy with the children and forgot to 
record the food intakes. The investigator attempted to record what she could remember, but the subject was unable to recall all food intakes during those days. The importance of a diabetic diet and significance of maintaining the record of daily food intake during the study period was explained to the subject. She did maintain the proper records for the following days of the study.

During the treatment phase her 4-day record (she missed recording her diet intake for 2 days out of 6 ) showed that the starch and bread intake was $59.9 \%$, the fruit exchange was not sufficiently balanced (four fruit exchanges in one day and none on the other days), only one exchange of meat substitute was used in this period, and she had sweets and desserts 3 times in this period. Her breakfast and lunch meals were at regular times, but the dinners were usually late. Her compliance level was unacceptable.

During the reinforcement phase, her intake of starch and bread exchange increased up to $150.6 \%$ of her recommended daily allowance. She still was not adding meat substitute and sufficient fruit exchanges in her daily diet menu, but her fat exchange was at the recommended level. Her average calorie intake during the 10-day study, for starch/bread exchange was $84.2 \%$, for meat and meat 
substitutes was $1.0 \%$, and for fat was $35.0 \%$ of her 1500 calorie prescribed diet (see Table 2, S5). On the last home visit, the investigator recommended that the subject see her physician because of her persistent high blood sugar levels, and that she should check and monitor her blood sugar daily.

Two weeks after the completion of the reinforcement phase her blood sugar level was 266 . The investigator, in addition to making recommendations to the patient, explained to the subject's daughter the significance of the diabetic diet plan and emphasized the importance of the subject following closely the recommended diet. Subject 6

Subject 6 was a 73 year old female who had been diabetic for 23 years. Her prescribed oral hypoglycemic agent was Diabeta $5 \mathrm{mg}$, two tablets every morning. She had been in the United states for 14 years during which time she had been treated for hypertension. She was 10 pounds over her normal weight and her physician had prescribed a 1500 calorie diet plan. She lived with her husband, daughter, and a grand-daughter. On the first day of baseline data collection, her blood pressure was $200 / 86$. The investigator immediately reported the result to her physician. The subject had an appointment the same day with the physician. 
The subject cooked for herself and her family. According to her food questionnaire, she ate three meals a day and had snacks with tea at about 4:00 PM daily. She ate Punjabi food and used bread occasionally to substitute for chapati (Indian bread). She dined out only at the temple approximately twice a week. Her frequently used seasonings were ketchup, chutney, hot pepper sauce, spices, butter, oil, ghee (clarified butter), panir (homemade thick white cheese), $2 \%$ low fat milk, and sugar which she used to make Indian sweets and desserts. Her pretest score on diabetic knowledge was 64 which improved to 94 at the posttest (see Figure 1, 56).

Her blood sugar levels were tested by the investigator approximately 2 hours after her lunch each day. Her average blood sugar levels were 284 during the baseline data collection phase, 238.5 during the treatment phase, and 180.5 during the reinforcement phase. Two weeks after the completion of the reinforcement phase, during a follow-up visit, her blood sugar level was 162. (see Table $1, S 6)$.

During the baseline data collection phase, her diet diary showed $157.4 \%$ of starch and bread intake instead of $50.0 \%$ which was the recommended consumption. She had no meat substitute exchange in her menu. Her intake of vegetable and fruit exchange groups was not sufficient. 
Her fat intake was $43 \%$ instead of recommended $30 \%$ of her total calories. She had food containing sugar on both days. Her compliance was at an unacceptable level. During the treatment phase her starch and bread exchange intake decreased to $73.2 \%$ of the total calories. This intake was still not down to the recommended level of $50.0 \%$. She added a meat substitute exchange in her diet meals only two times during the 6-day study period. The fruit exchange in her menu during this phase was not sufficient. Her level of compliance was still at an unacceptable level.

Her average starch and bread exchange intake during the 2-day reinforcement phase was $10.5 \%$. She did not have any consumption of meat substitute in her diet. She had one fruit exchange on the 9 th day and none on the 10th day. Her fat exchange intake for the 2 days was 4.5 instead of three exchanges a day. Her milk intake was three exchanges on each day instead of the recommended two per day.

Her mean consumption of 10-day calorie intake was $82.5 \%$ for starch and bread exchange, $1.0 \%$ for meat exchange, and $40.0 \%$ for fat exchanges. Her level of compliance remained unacceptable. The investigator explained to the subject how to calculate the fat exchange in her diet when she used oil for cooking. Also, explanations were provided in the use of dried legumes, 
lentils, kidney beans, and potatoes as part of the starch and bread exchange group, rather than considering them as from the vegetable group.

Two weeks after the completion of the reinforcement phase her blood sugar level was 162 which indicated a favorable trend of compliance and a positive effect of the diet teaching. The recommendations to this subject were to use artificial sweetener as a seasoning instead of regular sugar, and continue including fruit and meat exchange groups in her diet meals.

Interpretation of Findings

The age range of the 6 participants was from 52 to 73 . There were 2 males who were non-vegetarians and 4 females who were vegetarians. Two participants out of 6 subjects spoke English and the other 4 had family members who could speak English. All the participants were on a 1500 calorie prescribed ADA diet, but none of them strictly adhered to the recommended diet.

The pretest and posttest data reflected the responses of the subjects regarding their knowledge of diabetes and the diabetic diet. The range of scores in the pretests was $64 \%-85 \%$, and in the posttest was $91 \%-97 \%$. There were improvements from the pretest to the posttest scores of all subjects in their knowledge of diabetes (see Figure 1). 
After the teaching, the scores increased by amounts varying from $8.2 \%$ to $46.9 \%$

Constructs from orem's (1991) supportive-educative system and Bandura's (1977) social learning theory were applicable for 5 subjects, 1 male and 4 females. All 5 subjects were able to perform and able to learn care measures, but needed the investigator's counselling and teaching (supportive-educative system) to develop their knowledge and skill in diabetes and its dietary management. Five subjects were able to follow by observing and imitating the teachings of investigator and were able to restate what was observed, thereby supporting the social learning and imitation theory of Bandura. Although Subject 3, who was male, was physically and mentally able to follow his diet regimen, he was totally dependent on his wife and daughter-in-law. His cultural norm was one of dependency in meeting his self-care needs. He needed Orem's partially compensatory nursing system.

During the baseline data collection phase of the study, Subjects 2, 3, and 5 had blood sugar levels of 76, 70, and 112 respectively. These results were probably related to the intake of hypoglycemic medication without eating breakfast.

During the treatment phase, the trend of the blood sugar levels was one of decline for all subjects except for 
Subjects 4 and 5 (see Figure 2 and Table 1). The blood sugar levels of subject 4 increased during the 6 th, 7 th, and 8 th day of this phase. However, his mean value of blood sugar level for the treatment phase was 141.5 which showed improvement when compared to the baseline mean value of 174.5. The blood sugar levels of subject 5 had an upward trend. This may be due to the subject's lack of complete knowledge of her diabetic diet control regimen. Diabetic diet education was provided in teaching sessions which were scheduled for 30 minutes each day. All the facts about diabetic diet taught to each subject were not completed until the 6th day.

During the reinforcement phase, the mean blood sugar level of Subject 4 showed a further decline when compared with the treatment and the baseline phases. subject 5 remained on the upward trend in the reinforcement phase. The mean blood sugar levels of subjects 1, 2, and 5 were higher duxing this two-day reinforcement phase when compared to the mean values during the treatment and the baseline phases (see Table 1). However, the mean blood sugar levels for Subjects 1 and 2 (181.5 and 172 respectively) were below normal in the reinforcement phase. The criterion for normal blood sugar level among the Type II diabetic patients is that the 2-hour postprandial value should be less than $200 \mathrm{mg} / \mathrm{dl}$ (Olson, 1988, p. 20). 
Analyses of the diet diaries showed that the compliance levels of all the 6 subjects were unacceptable according to the ADA's target nutritional goals in all phases. The recommended intakes by the ADA (1988) for diabetes nutrition management are carbohydrate up to 55 to $60 \%$ of total calories, protein $12-20 \%$ of total calories, and fat less than $30 \%$ of total calories. The subjects' diet diaries show that most of their intake calories came from the starch and bread exchange groups (see Takle 2). The meat and meat substitutes and the fruit exchange groups were not sufficient in every subject's meal intake. Furthermore, all of the subjects during the 10-day study period had food with two to three times the recommended sugar content in their diets. However, the declining trend of the blood sugar levels of all subjects, except subject 5, indicated that there was a positive impact of the ethnically tailored diet education program and the diet plan was followed to some extent.

The record showed that subject 1 included all six exchange groups, and did not skip any meals. His diet compliance level became acceptable during the study period. He decreased the alcohol drinks from four to two per week. Although the blood sugar level for Subject 2 rose to 208 in the reinforcement phase, she started to cut down on the starch and bread exchange groups in her diet plan during 
the treatment phase. Subject 3 showed little improvement in his diet compliance. However, he did decrease the intake of starch and bread exchange groups and increased the intake of fruit exchanges. Also, he recognized the effect of alcohol on blood sugar level and started to count the calories from alcoholic beverage intake in his diet meals. Subject 4 demonstrated improvement in her diet compliance. She decreased the intake of starch and bread exchange groups. Furthermore, she started to count potatoes, lentils, and peas in the starch group instead of in the vegetable group. The interpretation of her mean blood sugar levels reveals that she complied with her diet plan throughout the treatment and reinforcement phases. subject 5 showed no improvement in her diet compliance. Although her pretest and posttest scores showed that she had knowledge of diabetes, she was not willing to change her daily pattern of eating habits. Her level of compliance stayed unacceptable.

Towards the end of the 1.0-day study period, the results of the blood sugar levels did show a reduction to the normal range for subjects $1,2,4$, and 6 . The response was even more pronounced when blood sugar tests were taken 2 weeks after the completion of the study period. These tests indicated acceptable compliance by all the subjects except subject 5, and suggested that, although the 
consumption of food exchanges was not adequate or in total adherence to the ADA diet plan, the ethnically tailored dietary teaching resulted in some positive changes. Subjects' ethnic diets became much more balanced. In addition, the subjects realized the importance of regular meal times, not skipping meals, planning diet meals with the recommended food exchanges, and recognizing the differences between the starchy and non-starchy vegetable groups.

The key recommendations regarding the diet regimen for all subjects were to reduce their carbohydrate intake, to increase fruit and meat exchange groups in their meals. Also, it was recommended not to count the starchy vegetables in the vegetable exchange group.

In summary, the analysis of data from this study suggested that there was a positive effect of the ethnically tailored diabetic diet education plan on dietary compliance in a group of 6 elderly diabetic Punjabi Americans. 


\section{Chapter 5}

DISCUSSION

Summary of study

The focus of this study was on the effect of ethnically tailored diet education for a group of 6 diabetic Punjabi elderly subjects. The participants ranged in age from 50 through 75 years with a mean age of 64.8 . Four were female and 2 were male. They all lived with their families.

The research was descriptive, utilizing a modified case study approach. The purpose of this study was to replicate and expand Kim's (1986) study of dietary compliance with a group of non-insulin-dependent diabetic Punjabi American elderly when diet teaching was ethnically tailored. All participants had NIDDM and were on an oral hypoglycemic agent. The convenience sample was selected from the membership of a local sikh temple. Four of the subjects were referred by a Punjabi physician who had a private practice in the same local area. The other 2 were not referred by a physician but were temple members. The study was done for a period of 2 weeks plus a follow-up. In the main study there were three phases: (a) the baseline data collection phase, (b) the treatment and teaching phase, and (c) the reinforcement phase. Daily diet diaries were maintained throughout the three phases. 
The blood sugar tests were performed daily by the investigator and results recorded during all phases of the study. The pretest and the posttest questionnaires were kept the same to examine the diabetic knowledge gained from the diet education plan. Two weeks after the completion of the 10-day treatment plan, follow-up home visits were made to review the dietary management, and to test the blood sugar level for compliance. The data were analyzed and results compared to evaluate effectiveness of the diet plan.

\section{Conclusions}

Conclusions from this study were based on the findings from the results of the pretests, posttests, diet diaries, and the results of the blood sugar tests. A comparison of the scores of the pretest and the posttest showed a significant knowledge gain regarding diabetic disease process and diabetic diet among all six subjects (Figure 1). After the teaching, the range of scores had increased from $8.2 \%$ to $46.9 \%$ and an average gain was $22.4 \%$. The results of the blood sugar levels indicated a declining trend among all subjects, except subject 5 (refer to Figure 2 and Table 1, S5). The overall average decrease in blood sugar levels of all subjects was $8.0 \mathrm{mg} / \mathrm{dl}$ within the 10-day study period. The noncompliance with the dietary regimen by subject 5 , whose blood sugar level 
remained on an upward trend throughout the study period, resulted in this small mean value of $8.0 \mathrm{mg} / \mathrm{dl}$. However, the declining trend of other subjects indicated that the diet teaching program was beneficial on the whole. This decline was more strongly confirmed by the blood sugar tests which were obtained during follow-up visits 2 weeks after the completion of the 10-day treatment plan (see Table 1).

The resuits frrom the diet aiaries inaicatea that the compliance of all the subjects was unacceptable when compared with the ADA's target nutritional goals, but the blood sugar levels show a reduction to the normal range for Subjects 1, 2, 4, and 6. This indicates that, although the consumption of food exchanges did not meet the standard set forth in the ADA diet plan, ethnically tailored diet teaching had a positive effect on diabetic dietary compliance. All the subjects showed interest in learning about the disease process and dietary management. An increase in knowledge and interest shown by subjects could "open the window" to diabetics frequently lacking in motivation and compliance, and bring about effective behavioral changes that last a lifetime. Scope and Limitations

The scope of research on diabetic dietary compliance is very broad and flexible, encompassing a wide range of 
topics. The scope of this particular descriptive study, however, is limited. It was a replication of a previous study and constrained to a local and specific cultural setting. This limits the ability to generalize to the larger diabetic population. The reasons for replication of this study were (a) to make modifications to improve the quality of the previous study, (b) to determine whether Kim's (1986) findings will hold up in different settings anü witin tine passage of time, and (c) to deterimine whether the information generated from additional studies is consistent with the original study findings and useful in nursing practice.

Other limitations of this study include:

1. Since the size of the sample was so small, this study cannot be generalized to the elderly population as a whole.

2. There was no control group with which to compare the effectiveness of treatment. However, it is proposed that this study will contribute knowledge that may serve to stimulate additional studies.

3. The reliability and validity of the measurement instruments have not been established.

4. The participants may have been eating more adequate diets during the study because they had to record their food intakes. 
5. The long range adherence and the effectiveness of the diet plan cannot be demonstrated, because the short period--2 weeks--of this study did not provide sufficient time for monitoring and verifying compliance. Recommendations

The results of this study demonstrate a need for future investigation. Recommendations for future studies include:

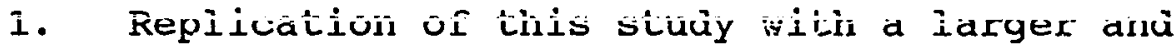
randomized sample in multiple locations of northern California to allow for generalization of the findings among the Punjabi Americans.

2. Research should be conducted to further test the measurement instruments in an effort toward improving their reliability and validity.

3. Diabetic diet and health information should be extended into many different ethnic communities and the effect of this education on compliance measured.

4. A comparison study could also be done between insulin and non-insulin-dependent diabetic elderly for further understanding of the same population. 
REFERENCES

70 
References

Ahmad, W.I., Baker, M.R., \& Kernohan, E.M. (1991). General practitioners' perceptions of Asian and non-Asian patients. International Journal of Family practice, $\underline{8}(1), 52-56$. Allawi, J., Rao, P.V., Gilbert, R., Scott, G., Jarrett, R.J., Keen, H., Viberti, G.C., \& Mather, H.M. (1988). Microalbuminuria in non-insulin-dependent diabetes: Its prevalence in Indian compared with Europid patients. British Medical Journal, 296, 462-464

American Diabetes Association. (1979). Principles of nutrition and dietary recommendations for individuals with diabetes mellitus. Diabetes, 28, 1027-1029.

American Diabetes Association. (1988). Nutrition guide for professionals: Diabetes education and meal planning. The American Diabetes Association Publication No. ISBN 0-945448-04-X. Washington, DC: U.S. Government Printing office.

American Diabetes Association. (1991). Therapy for diabetes mellitus and related disorders. The American Diabetes Association Publication No. ISBN 0-945448-16-3. Washington, DC: U.S. Government Printing office. 
Bandura, A. (1977). Social learning theory. Morristown, NJ: General Learning Press.

Bhopal, R.S. (1986). Bhye Bhaddi: A food and health concept of Punjabi Asians. Journal of Social Science and Medicine, $\underline{23}(7), 687-688$.

Blevins, D. R. (1979) - The diabetic and nursing care. New York: McGraw-Hill.

Bureau of the Census. (1992). 1990 Census of population and housing (Report No. $1990 \mathrm{CPH}-1-1$ ). Washington, DC: U.S. Government Printing office.

Burns, N., \& Grove, S.K. (1987). The practice of nursing research: conduct, critique and utilization. Philadelphia: W.B. Saunders

Fawcett, J. (1989). Analysis and evaluation of conceptual models of nursing. Philadelphia: F.A. Davis.

Freimer, N., Echenberg, D., \& Kretchmer, N. (1983). Cultural variation: Nutitional and clinical implications. The Western Journal of Medicine, $\underline{139}(6), 929-933$.

Fujimoto, W.Y. (1985). Diabetes in Asian Americans. National Institute of Health (NIH) Publication No. 85-1468. Washington, DC: U.S. Government Printing Office. 
Funnell, M.M. (1990). Role of the diabetes educator for older adults. Diabetes Care, 13 (suppl. 2), 60-65. Gambert, S. R., Cooppan, R., \& Gupta, K. (Eds.) (1990) . Diabetes mellitus in the elderly. New York: Raven Press.

Gupta, O.P., Sarita, B., Srivastava, P., \& Chaurasia. A.K. (1987). Role of maize bran on cardiovascular status, lipid profile and glycaemic control in diabetes mellitus. Journal of Association of Physicians of India, 35(5). 353-355.

Hodgson, K. (1989, December). A responsive service: Health education for Asians with diabetes. The Professonal Nurse, pp. 129-133.

Kim, E. (1986). The effect of ethnically tailored diet education with diabetic Koreans. Unpublished master's thesis, San Jose State University, San Jose, CA. Lefrancois, G.R. (1985). Psychology for teaching (6th ed.). California: Wadsworth.

Lipson, L.G., \& Kato-Palmer, S. (1988, September). Asian Americans. Diabetes Forecast, pp. 48-51.

LoBiondo-Wood, G., \& Haber, J. (1990) . Nursing research: Methods, critical appraisal, and utilization (2nd ed.). St. Louis, MO: Mosby. 
Marmot, M., \& Syme, L. (1976). Acculturation and coronary heart disease in Japanese-Americans. American Journal of Epidemiology, 104, 225-247. Mather, H.M., \& Keen, H. (1985). The Southhall diabetes survey: Prevalence of known diabetes in Asians and Europeans. British Medical Journal, 291, 1081-1084. Mcculloch, D.K., Mitchell, R.D., Ambler, J., \& Attersall, R.B. (1983). Influence of imaginative teaching of diet on compliance and metabolic control in insulin dependent diabetes. British Medical Journal, 287, $1858-1861$.

McKeigue, P.M., Shah, B., \& Marmot, M.G. (1991).

Relation of central obesity and insulin resistance with high diabetes prevalence and cardiovascular risk in South Asians. The Lancet, 337, 382-386. Metropolitan Life Insurance Company. (1983). Height and weight tables for men and women. Statistical Bulletin, $\underline{64}(1), 2-8$.

Ney, D., Stubblefield, N., \& Fischer, C. (1983). A tool for assessing compliance with a diet for diabetes. The American Dietetic Association, 82 (3), 287-290. Odugbesan, O., \& Barnett, A.H. (1985). Asian patients attending a diabetic clinic. British Medical Journal, 290, 1051-1054. 
Olson, O.C. (1988). Diagnosis and management of diabetes mellitus (2nd ed.). New York: Raven Press.

Orem, D.E. (1990). Nursing: Concepts of practice (3rd ed.). New York: McGraw-Hill.

Perkins, M.R., Plehwe, W.E., Hosking, M.N., \& Turtle, J.R. (1985). A high prevalence of obesity in a diabetic population: Results of a survey of food patterns in 252 patients in a 2 year period. Diabetes Research and Clinical Practice, 1, 9-20. Powers, M.A. (1987). Handbook of diabetes nutritional management. Maryland: Aspen. Raheja, B., Modi, K., Barua, J., Jain, S., Shahani, V., \& Koppikar, G. (1987) . Proliferative diabetic retinopathy in NIDDM and Indian diet. Journal of Medical Association of Thailand, 70 (suppl. 2), $139-143$

Singh, P.P., \& Chawla, R.P. (1988). Insecticide residues in total diet samples in Punjab, India. The Science of the Total Environment, 76, 139-146.

Singh, R.S. (1986). Bhye Bhaddi: A food and health concept of Punjabi Asians. Journal of Social Science Medicine, $\underline{23}(7), 687-688$. 
Woods, N. (1989). Conceptualizations of self-care:

Towards health-oriented models. Advances in Nursing

Science: Self-Care Issues, 12(1), 1-13. Maryland:

Aspen.

Zimmet, P., Taylor, R., \& Ram, P. (1983). The

prevalence of diabetes and impaired glucose

tolerance in the biracial (Melanesian and Indian)

population of Fiji: A rural-urban comparison.

American Journal of Epidemiology, 118, 673-688. 
APPENDIX A

Goals and Objectives 
Goals and objectives of the Treatment

Goals

1. Maintain blood sugar as near as the normal physiologic range as possible.

2. Attain and maintain optimum nutrition.

3. Attain and/or maintain an ideal body weight.

4. Make the diet prescription as attractive and realistic as possible using appropriate ethnic and western foods as needed.

objectives

At the end of the treatment each subject will be able to :

1. Tell the importance of diet.

2. Recite the signs of the hyperglycemic and hypoglycemic reactions and their treatment.

3. Name six exchange groups.

4. Match food with the correct exchange group.

5. Make a menu with correct exchange groups.

6. Distinguish undesirable foods.

7. Tell three desirable ways of cooking methods.

8. Tell three precautions in shopping.

9. Identify three desirable strategies for dining out. 
APPENDIX B

Outline of Teaching Course and Data Collection Schedule 
Outline of Teaching course and

Data Collection Schedule

\section{Phase 1: Baseline Data}

Day 1.

(a) Share the purpose of the study, the subject's participation, and obtain the subject's consent on the form.

(b) Collect demographic data and medical history.

(c) Complete food questionnaire to gather previous dietary habits.

(d) Initiate the diet diary and encourage the subject to record all meals consumed.

(e) Perform initial blood sugar test.

Day 2. (a) Complete the pretest to assess the subject's knowledge of diabetes and diet.

(b) Review the diet diary and explain the importance of maintaining the diet diary during the course of the study/treatment.

Phase 2: Treatment

Day 3. (a) Share the goals and objectives of the treatment phase. Explain the teaching schedule.

(b) Explain the importance of diet as a treatment.

(c) Explain the signs and symptoms of hyperglycemic and hypogiycemic reaction and what to do.

Day $\therefore$ (a) Share why the physician prescribes limited calories.

(b) Teach six food exchange groups.

Day 5. (a) Share how to use exchange lists.

Day 6. (a) Make a sample menu from the list. 
outline of Teaching Course and Data Collection Schedule (Continued):

Day 7. (a) Create awareness of appropriate and inappropriate foods.

(b) Share how to select/shop and prepare foods.

Day 8. (a) Share how to dine out.

Phase 3: Reinforcement

Day 9. (a) Share individual questions and answers.

(b) Review overall diet diaries. Correct or replace as necessary.

Day 10. (a) Complete the posttests.

Followup: Visit after 2 weeks from day 10.

Day 24. (a) Obtain blood sugar levels and review dietary compliance.

Note: During each visit, the researcher will:

(a) test and monitor the blood sugar level of each participant.

(b) review the diet diary for completeness and compliance. 
APPENDIX C

Consent Letter 
Dear

You are being invited to participate in a study regarding a diabetic diet tailored to Punjabi foods and cooking methods. I hope to learn whether or not an ethnically tailored diet will improve dietary compliance in our diabetic Punjabi population.

If you decide to participate, I will visit you in your home for 2 weeks except weekends. I will ask you about your physical, medical, and social background, and I will ask you to answer a pretest about your knowledge of diabetes.

You will be asked to keep a daily record of your diet for 2 weeks. I will test your blood sugar 5 days a week for 2 weeks. The blood sugar test will be done by the fingerstick method. There is a minimal possibility of a fingerstick infection. However, extreme care will be exercised in performing the fingerstick blood test to minimize risk of such infection.

By checking and recording your blood sugar level, and by having the diet record, your doctor san be assisted in adjusting your medication, or in determining the need for further testing to be done. You will learn about a diabetic diet that is modified to our Punjabi dietary customs. By learning about your dietary habits, you may have more control over your diet and your disease.

Any information obtained in connection with this study, and any information identified with you will remain confidential and will be disclosed only with your permission, or as required by law.

Your decision whether or not to participate will not prejudice your fiuture relations with your doctor. If you decide to participate, you are free tc sithdraw your consent and to discontinue participation at any time without prejudice.

If you have any questions, please do not hesitate to ask. If you have any additional questions in the future during the course of study, I will be happy to answer them. 
Letter of consent (cont'd)

For any question about the research please contact Naranjan K. Singh at (408) 997-3867. Complaints about the research may be presented to Dr Betty sensiba at (408) 924-3139. Questions or complaints about the research Subject's Rights or research related injury may be presented to Dr. Serena Stanford, PhD, Associate Academic Vice President for Graduate Studies at (408) 924-2480.

YOU ARE MAKING A DECISION WHETHER OR NOT TO PARTICIPATE. YOUR SIGNATURE BELOW INDICATES THAT YOU HAVE DECIDED TO PARTICIPATE, HAVING READ THE INFORMATION PROVIDED ABOVE.

Date

Signature

witness Investigator 
APPENDIX D

Food Questionnaire Form 
Food Questionnaire

Subject Name:

1. How many meals do you eat a day?

2. Is your meal time regular?

yes no no

3. Do you mainly eat Punjabi food?

yes no

4. Do you eat westernized food?

yes no If so, please list westernized food and how often:

5. How often do you eat out a week?

6. Circle the seasonings/spices/condiments/sauces you frequently use:

red pepper sugar

garm massala butter

ketchup margarine

chutney oil

hot pepper ghee (clarified butter)

sauce (buffalo or $\mathrm{cow}^{\prime} \mathrm{s}$ )

Panir (thick white cheese)

Coconut water, milk, or cream 
APPENDIX E

Pretest and Posttest 
Pretest and Posttest

Subject Name:

Date:

This is a True-False test. Please circle correct answer:

$T=$ TRUE $\quad F=$ FALSE

\begin{tabular}{|c|c|c|c|}
\hline $\mathbf{T}$ & F & 1) & Diabetes can be cured \\
\hline $\mathrm{T}$ & $\mathbf{F}$ & 2) & $\begin{array}{l}\text { As long as I take the oral hypoglycemic, I do } \\
\text { not have to worry about diet. }\end{array}$ \\
\hline $\mathrm{T}$ & $\mathbf{F}$ & 3) & $\begin{array}{l}\text { Being overweight increases insulin needs and } \\
\text { complicates control of diabetes. }\end{array}$ \\
\hline $\mathbf{T}$ & $\mathrm{F}$ & 4) & $\begin{array}{l}\text { It does NoT matter whether I eat meals at } \\
\text { irregular times each day. }\end{array}$ \\
\hline $\mathbf{T}$ & $F$ & 5) & $\begin{array}{l}\text { A diabetic person has to avoid foods high in } \\
\text { sugar content, such as candy, cake, jelly, } \\
\text { Punjabi sweets, honey, and sort drinks. }\end{array}$ \\
\hline $\mathrm{T}$ & $F$ & 6) & Alcohol does NOT affect blood sugar. \\
\hline $\mathbf{T}$ & $\mathrm{F}$ & 7) & $\begin{array}{l}\text { A diabetic person should avoid foods high in } \\
\text { saturated fats and cholesterol. }\end{array}$ \\
\hline $\mathbf{T}$ & F & 8) & $\begin{array}{l}\text { It is better to bake, broil, roast on a rack, } \\
\text { or stew rather than fry foods. }\end{array}$ \\
\hline $\mathbf{T}$ & $\mathbf{F}$ & 9) & $\begin{array}{l}\text { To prevent Low blood sugar reaction, } \\
\text { medication and meals should be taken on time. }\end{array}$ \\
\hline $\mathrm{T}$ & $\mathbf{F}$ & 10) & $\begin{array}{l}\text { A diabetic person should be aware of hidden } \\
\text { fats in foods. }\end{array}$ \\
\hline
\end{tabular}

Please circle the foods that have hidden fats:

french fries, chips, pakoras, samosas, parothas, cheese, whole milk, mayonnaise, nuts, fish, fried shrimp

Please circle the foods that have high saturated fats:

beef, chicken, lamb, goat, ham, bacon, pork, fish, organ meat, cheese, soybean 
APPENDIX F

Demographic Data Form 
Demographic Data

Name:

Sex:

Weight:

Educational Level:

English: Read:

Punjabi: Read:

Female

Height:
Age:

BP :

Pulse:

Religion:

How long have you been in the U.S.?

Family history of diabetes mellitus:

Any physical disability?

Current medication:

Do you exercise?

Do you live with someone?

Who does most of cooking?

Are You Vegetarian? Non-vegetarian?

Prescribed calorie intake: 
APPENDIX G

Diet Diary Form

91 
Diet Diary

Daily Record for Each Time Food is Consumed

Name:

Date:

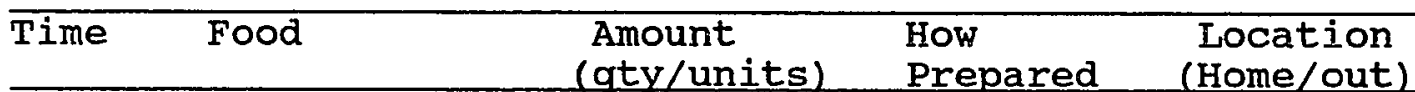

